\title{
Tactile Discrimination Capacity in Relation to Size and Organization of Somatic Sensory Cortex in Primates: I. Old-World Prosimian, Galago; II. New-World Anthropoids, Saimiri and Cebus
}

\author{
Mary Carlson and Pia Nystrom \\ Department of Neurobiology, Harvard Medical School, Boston, Massachusetts 02115.
}

Living primates vary considerably in brain organization, in sensorimotor and cognitive abilities, and in natural behavioral repertoires. Comparative studies of primary (SI) and secondary (SII) somatic sensory cortex of primates reveal major differences in the size and in the complexity of topographic projection patterns. The separate projections of the glabrous hand to SI cytoarchitectonic areas $3 b$ and 1 described in the Old World (OW) anthropoid Macaca and in New World (NW) anthropoids Cebus, Saimiri, and Aotus are lacking in NW Saguinus and in the prosimian Galago. The relationship between the size and complexity of SI organization and tactile abilities is explored in this study of four species of primates-Galago, Macaca, Cebus, and Saimiri. These species were trained to discriminate between pairs of objects differing either in cross-sectional diameter (size) or surface roughness (texture). The course of acquisition of such tactile discrimination in normal Macaca and the nature of deficits following SI or SII removals are known. Selective lesions of either cytoarchitectonic area 1 or 2 in Macaca affect only texture or size discriminations, respectively. Removal of area $3 \mathrm{~b}$ in SI, or of SII, in Macaca affects both size and texture capacities. The single projection of the glabrous hand to area $3 b-1$ of Galago led to our expectation that the capacity of Galago to discriminate textures would be more similar to an area 1-lesioned than to a normal Macaca. The substantial and persistent differences between Macaca and Galago on texture, but not size, tasks lend support to the view that the evolution of a second projection of the glabrous hand to area 1 in Macaca contributes to increased texture discrimination capacity. The similarity in multiple projection patterns of the glabrous hand to areas $3 b$ and 1 in Macaca, Saimiri, and Cebus led us to expect greater correspondence in texture discrimination capacity between these three anthropoids than to Galago. Contrary to expectations, Saimiri and Cebus showed a tactile capacity more similar to Galago than to Macaca. Furthermore, the texture discrimination capacity of Cebus actually improved substantially after re-

\footnotetext{
Received Mar. 8, 1993; revised June 25, 1993; accepted Aug. 261993

This research was supported by DHHS-PHS Grant MH 40157 (M.C.) and the McDonnell Center for Study of Higher Cortical Function (M.C.), Washington University School of Medicine, St. Louis. We thank Kim Fritz and Lori Rosenthal for their artistic contributions to the illustrations and Joc Gagliardi for skillful photography. We are grateful to Jon Kaas, Todd Preuss, and Felton Earls for their thoughtful comments on the manuscript.

Correspondence should be addressed to Mary Carlson, Department of Neurobiology, Harvard Medical School, 220 Longwood Avenue, Boston, MA 02115.

Copyright (C) 1994 Society for Neuroscience $0270-6474 / 94 / 141516-26 \$ 05.00 / 0$
}

moval of area 1 . This provides further evidence, together with the single SI hand area in NW Saguinus and Galago, that the separate cutaneous projections to area 1 in $O W$ and NW primates are not homologous but evolved independently and possibly serve different tactile functions.

[Key words: tactile, discrimination, cortex, primates, behavior, evolution]

The comparative study of neural organization and of behavioral capacity has provided important insights into brain-behavior relations in a wide variety of vertebrates. By comparing speciestypical features of the mammalian cerebral cortex with related sensory, motor, or cognitive functions, one can consider the role of localized cortical areas in specific behavioral capacities in this major class of vertebrates. Such an approach, in the order Carnivora, has been used to show that the density of peripheral receptors and relative enlargement of central projections from diffcrent skin surfaces to primary somatic sensory cortcx (SI) correlate with the use of a surface in natural exploratory and discriminative behaviors in the family Procyonidae, which includes the raccoon, coati, and kinkajou (Welker et al., 1963, 1964).

The rich variety of existing primate species provides an unique opportunity for comparative studies of brain organization and behavior. The sicable number of field observations reported over past decades provides detailed information on the natural behavioral strategies of many species in current habitats. Continued examination of the taxonomic relations, based on both the fossil record and biomolecular evidence, between extinct and extant primates provides a firmer basis for the interpretation of comparative work on contemporary species. A major distinction in the study of primate phylogeny, critical to the interpretation of any comparative analysis of living primates, is that of the Old World (OW) and New World (NW) lineages.

The phylogenetic and geographical origin of the NW anthropoids and their taxonomic relationship to $\mathrm{OW}$ anthropoids remains one of the most intriguing questions in primate evolutionary biology. The first NW anthropoids appear abruptly in the fossil record in South America about 25 million years ago, without evidence that primates had previously existed on this continent. There are two alternative sources from which the NW anthropoids may have evolved-North American prosimian primates or early African anthropoids (Fleagle and Rosenberger, 1990). The few fossil remains recovered from South America do not provide conclusive evidence, but an African origin is favored because of shared morphological traits (Delson and Rosenberger, 1980; Fleagle, 1988). Through morphological 


\section{Galago crassicaudatus}
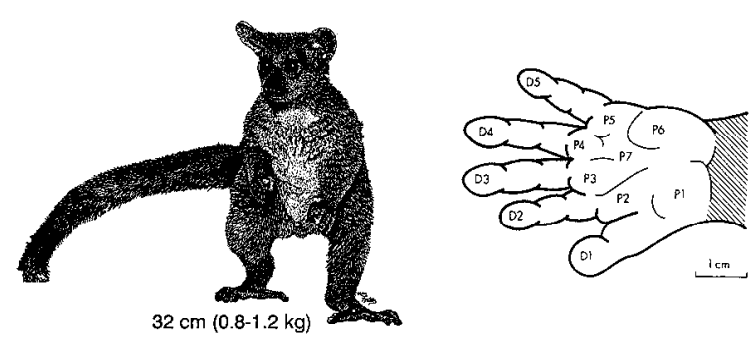

$32 \mathrm{~cm}(0.8-1.2 \mathrm{~kg})$

\section{Macaca fascicularis Macaca mulatta}
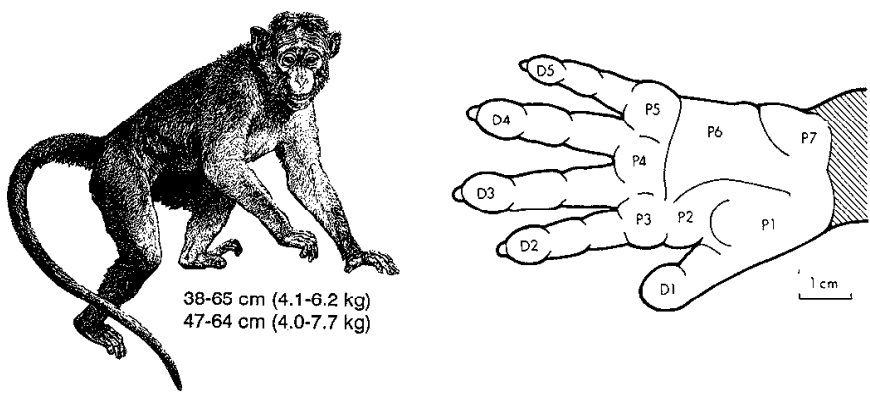

Figure 1. This drawing of the prosimian Galago crassicaudalus ( $G$. garnetti), commonly known as the greater bushbaby, presents a typical bipedal posture assumed in this species, characterized as a quadrupedal climber and upright leaper. Galago is a small primate, with a $32 \mathrm{~cm}$ average head-to-rump length (Macdonald, 1984). Average adult weight is $1 \mathrm{~kg}$, with little or no sexual dimorphism (Bearder, 1987). The drawing of the glabrous hand indicates the thumb (D1) medial to digits $(D 2-$ $D 5)$ and palmar pads (P1-P7) (adapted from Biegert, 1961). Galago has a generalized primate hand, used mainly for locomotion, capture, and feeding on insects. Galago, like most other prosimians, have a stereotyped whole-hand grasp, in which the digit tips contact the palm (Bishop, 1964). During grooming the lower front teeth (forming a specialized tooth comb) are used rather than the hands. When in the bipedal stance frequently assumed during threat, hands are used in fisticuffs combat (Bishop, 1964). The drawing of the OW anthropoid Macaca fascicularis, or crab-eating macaque, illustrates the quadrupedal posture assumed during locomotion. $M$. fascicularis is medium sized, with a shorter headto-rump length and more restricted range of body weights (upper numbers) than Macaca mulatta (lower numbers) or rhesus macaque (Macdonald, 1984). Both species are sexually dimorphic, with females on average $1-2 \mathrm{~kg}$ lighter than males.

comparisons of extant primate species it may be possible to infer phyletic relationships and evolutionary sequences. However, parallel evolutionary processes are not rare; therefore, it cannot be assumed that the presence of a shared morphological trait necessarily means that the functional aspects are homologous. This behavioral study compares the tactile discrimination capacity of Galago, a prosimian primate believed to have retained features of its brain and behavior that reflect an earlier stage of primate evolution 40-50 million years ago, to three anthropoid primates with more recent evolutionary histories: the OW Macaca, and NW Saimiri and Cebus (Napier and Walker, 1967; Radinsky, 1974; Carlson and Welt, 1981; Fleagle, 1988).

Among existing prosimians, presently found only in the Old World, Galago (family Lorisidae, subfamily Galaginae) is widely distributed across eastern and southern Africa. Its nervous sys-

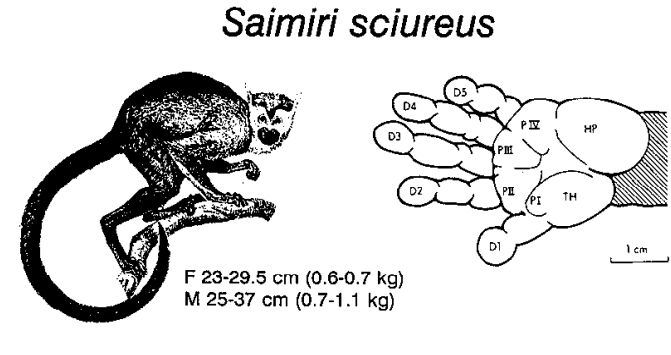

Cebus apella

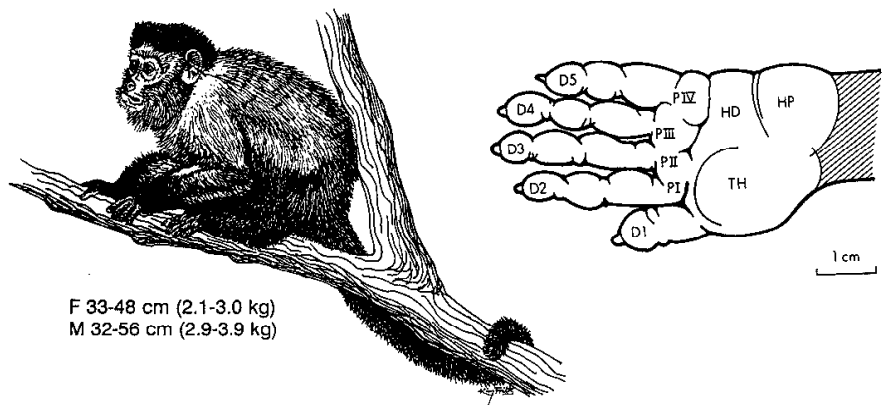

Figure 2. This figure shows body and hand drawings of the NW anthropoids Saimiri sciureus and Cebus apella. Both species are widespread throughout South America. Weight ranges for both species are given in the figure along with head-to-rump lengths (from Macdonald, $1984)$. The average weight for adult Saimiri females $(F)$ is $0.7 \mathrm{~kg}$, and adult males $(M), 1 \mathrm{~kg}$. Average weight for adult Cebus females is 2.5 $\mathrm{kg}$, and adult males, $3 \mathrm{~kg}$ (Robinson and Janson, 1987). The hand drawings identify the five glabrous digits $(D I-D 5)$, the palmar $(P I-P I V)$, thenar $(T H)$, hypothenar $(H P)$, and accessory hypothenar $(H D)$ pads (Biegert, 1961). Saimiri has comparatively short fingers and a short thumb with limited opposability. When grasping insects, the mainstay of their diet, Saimiri flex the joints between digits and palm. Cebus also have short fingers, but the thumb is opposable, and they exploit their manual strength and dexterity to grasp foods unavailable to other species (Fleagle, 1988).

tem is the most extensively studied of the prosimians and its behavior has been studied in its natural habitat. Among the widely diverse OW anthropoids, Macaca (family Cercopithecidae, subfamily Cercopithecinae) is the most widely distributed of the nonhuman primate infraorder and the most commonly studied laboratory primate (Fig. 1).

The NW genera Saimiri and Cebus (family Cebidae, subfamily Cebinae) are found throughout most of Central and South America. Like all NW primates, Saimiri and Cebus are arboreal and the smaller-bodied Saimiri frequently form mixed groups with the larger-bodied Cebus. Both genera are frequently used in laboratory studies and have been studied extensively in their natural habitats (Fig. 2).

In the somatic sensory cortex of primates, the glabrous hand is the skin surface with the greatest relative enlargement compared to other body parts (Carlson, 1985, 1990). In addition to the differential enlargement of skin surfaces, research on the somatic sensory system in primates has come to focus on the importance of the relative complexity of topographic patterns in the SI area in different species. Early macroelectrode recordings in SI of Macaca defined only a single major topographic pattern in SI spanning several different cytoarchitectural fields in the postcentral gyrus (Woolsey et al., 1942). More recently, microelectrode studies in Macaca revealed multiple topographic 


\section{Galago}
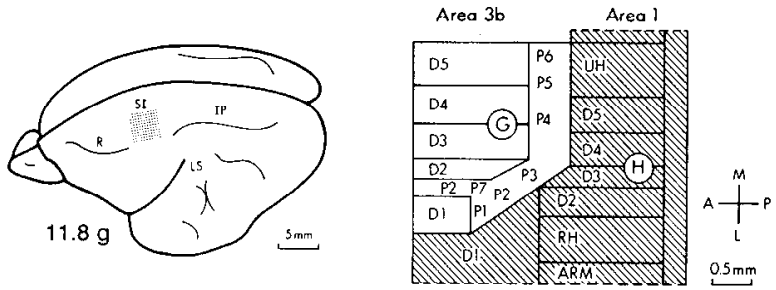

\section{Macaca}
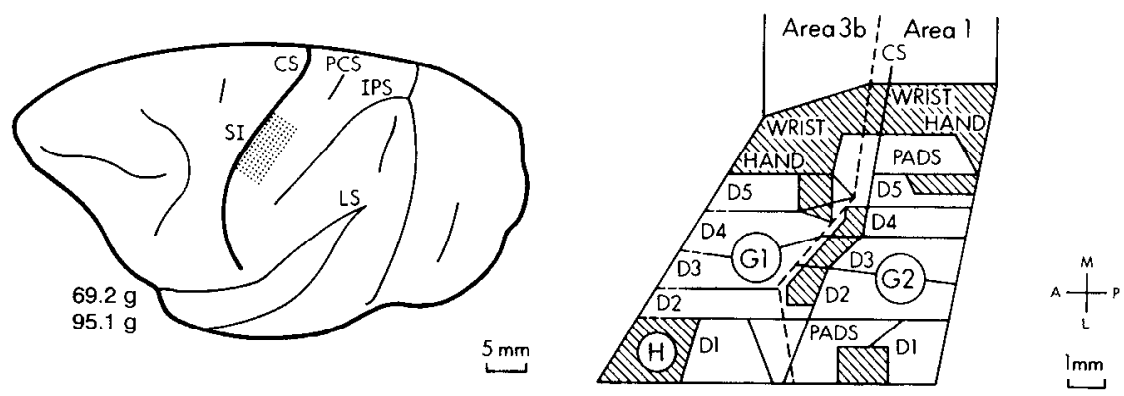

Figure 3. The drawings of the lateral surface of left hemispheres of Macaca and Galago show differences in number and orientation of sulci between the species. In Galago, SI is indicated by the shaded area located intermediate to the sagittally oriented rectus $(R)$ and intraparietal sulcus $(I P)$. Only a single hand area spans SI with the nonhairy or glabrous $(G$, white $)$ projecting to area $3 \mathrm{~b}$ and the hairy digits and ulnar $(U H)$ and radial $(R H)$ hand $(H$, hatched) projecting to area 1 and lateral 3b (G. crassicaudatus, Carlson and Welt, 1980; G. senegelensis, Sur et al., 1980). The location of the cutaneous input from the hand to the SI area in Macaca is indicated by shaded area behind the coronally oriented central sulcus $(C S)$. The major cutaneous projection area, area $3 \mathrm{~b}$, is located in the posterior bank of the central sulcus, with the second SI cutaneous area, area 1 , shown on the anterior crown of postcentral gyrus. In Macaca, the postcentral sulcus $(P C S)$ lies medially midway between central sulcus and intraparietal sulcus (IPS) and near cytoarchitectonic division of areas 1 and 2. In Macaca two separate glabrous projection patterns (G1 and G2, white) extend across areas $3 \mathrm{~b}$ and 1 , with a single, distributed hairy projection pattern $(H$, hatched $)$ across the two cytoarchitectonic areas $(M$. mulatta, Paul et al., 1972; M. fascicularis, Nelson et al., 1980). The division between areas $3 \mathrm{~b}$ and 1 is represented by a dashed line, while the curve from the crown to the anterior bank of the central sulcus is indicated by a solid line. The numbers under the anterior pole of each brain hemisphere indicate brain weights, for Galago (average) and separately for Macaca female (upper numbers) and male (lower numbers).

projection patterns from the glabrous hand to SI, corresponding to architectonic areas 3b, 1, and 2 (Paul et al., 1972; Nelson et al., 1980; Fig. 3). The use of "SI" in this article refers to the historical concept of the postcentral gyrus without reference to the debate about "SI proper" and issues of homology of areas $3 \mathrm{a}, 3 \mathrm{~b}, 1$, and 2 between primates and other mammals (Merzenich et al., 1978). Furthermore, these microelectrode mapping studies of SI have revealed differences in the size and topographic projection patterns of the glabrous hand and other body surfaces between prosimians, OW and NW anthropoids, as well as among the NW anthropoids.

In contrast to Macaca, we found only a single topographic pattern from the glabrous hand to area $3 \mathrm{~b}$ and from the hairy hand to area 1 of the African prosimians Galago (Carlson and Welt, 1977, 1980; Sur et al., 1980; Fig. 3) and Perodicticus (FitzPatrick et al., 1982). In the Asian prosimian Nycticebus, we reported a minor second glabrous projection within the major projection of the hairy hand to area 1 (Carlson and FitzPatrick, 1982). Our subsequent studies of secondary somatic sensory cortex (SII) in Galago demonstrated a single hand and body projection pattern (Burton and Carlson, 1986) with features similar to the single area defined in SII of Macaca (Robinson and Burton, 1980).

Like Macaca, the NW anthropoids Aotus (Merzenich et al.,
1978), Cebus (Felleman et al., 1983), and Saimiri (Sur et al., 1982) have separate projections from glabrous hand and other body surfaces in areas $3 \mathrm{~b}$ and 1 (Fig. 4), yet Saguinus, another NW species, has only a single hand and body projection area in SI, reminiscent of the Galago SI area (Carlson et al., 1986). Based on these results, it can be assumed that the last common ancestor of OW and NW anthropoids, whether of a prosimian or anthropoid grade, possessed only a single SI topography. Thus, when the existing comparative studies of SI cortical maps are examined relative to the phyletic relation between $\mathrm{OW}$ and NW species, it would appear that multiple SI areas seen in OW and NW species evolved independently after the divergence from a common ancestor.

The present studies were done to determine the capacity of these four species to acquire a series of size and texture discriminations of varying difficulty and to perform consistently on a composite task (the ALLS task) of the same series of discriminations. A comparison of the tactile capacity of Galago and Macaca relative to the size and complexity of their respective SI and SII hand areas allows for an estimation of the behavioral significance of the more recently acquired cutaneous projection to area 1 in SI in Macaca, which is lacking in Galago. By comparing the acquisition and performance scores of Galago and Macaca to Saimiri and Cebus and to the relative and ab- 


\section{Saimiri}
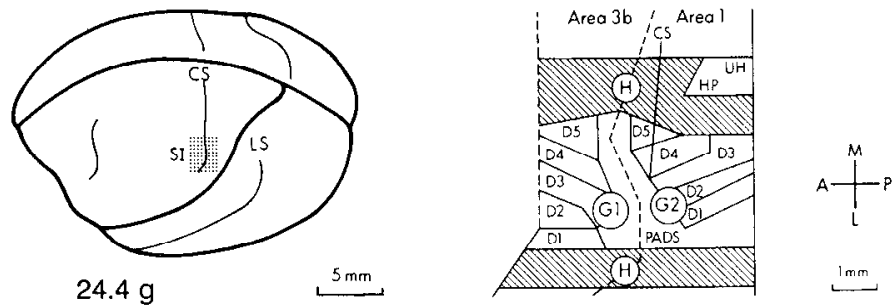

\section{Cebus}

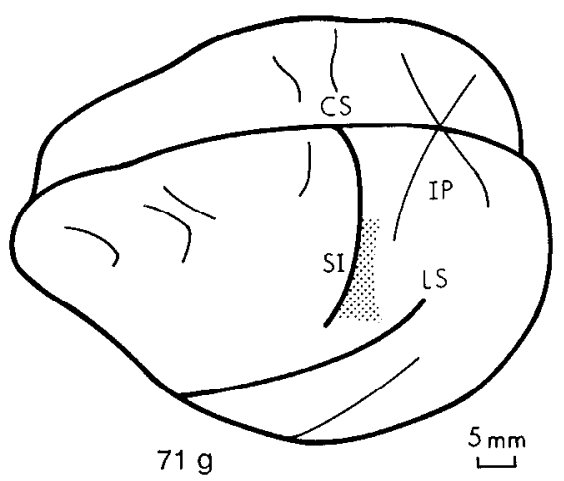

Figure 4. The drawings of the lateral surface of left hemispheres of Saimiri and Cebus show the location of cutaneous input to the SI hand area (shaded). Maps of the hand areas show the general topographic features of the input from the glabrous (nonhairy) digits and palm (white) and hairy digits and hand (hatched). In Saimiri the central sulcus (CS) does not divide the somatic sensory from the more anterior motor cortex but rather the central sulcus lics within SI (Sur et al., 1982). Input from the glabrous areas form two topographic patterns, $G l$ and $G 2$. The palm pads, hypothenar eminence $(H P)$, and ulnar hand $(U H)$ project to the margins of the $3 \mathrm{~b} / 1$ border and digits to anterior area $3 \mathrm{~b}$ and posterior area 1 . The hairy surface of the hand and digits $(H)$ projects primarily to the margins of the Gl and G2 patterns, though RFs on the dorsal hairy digits can be found within the areas $3 \mathrm{~b}$ and 1 glabrous hand region (Merzenich et al., 1987). The area $3 \mathrm{~b} / 1$ border is signified by a dashed line and the central sulcus by a solid line. The map of the Cebus SI hand area also shows two glabrous digit patterns ( $G 1, G 2)$ across areas $3 b$ and 1 . The topographic pattern of palm, hairy digits, ulnar $(U H)$, and radial $(R H)$ hand, and radial arm $(R A)$ is compressed in the areas medial and lateral to G1 and G2 (Cebus, Felleman et al., 1983; Saimiri, Sur et al., 1982). In contrast to Saimiri, and similar to Macaca, the digits project across the anterior-posterior expanse of areas $3 \mathrm{~b}$ and 1 and palm pads are located medial to the digit area. $I P$, intraparietal sulcus; $L S$, lateral sulcus. solute expansion of their SI cortical hand areas, the behavioral significance of evolutionary changes in cortical expansion and organization may be better understood.

The current study also provides new information on the expansion of the SI hand area relative to the projection areas of other body surfaces and to the actual glabrous skin area of the hand and foot. By obtaining actual measures of glabrous skin areas of all four species in this study, we are able to make estimates of the magnification factors in SI (and SII in Galago and Macaca) of cortical projection areas for the hand and foot. Our previous maps of SI in the greater Galago (see Materials and Methods below, concerning species designation) were restricted to the hand arca, with some adjoining receptive fields (RFs) from the arm and face area (Carlson and Welt, 1977, 1980). Those first maps of both awake and anesthetized Galago were intended to obtain the fine organizational detail of the cutaneous and noncutaneous input from the hand similar to microelectrode maps of the SI hand area in Macaca (Powell and Mountcastle, 1959; Paul et al., 1972). With an interest in estiInating the relative expansion of the hand, foot, and other body surfaces projecting to SI in greater Galago, it was important we obtain maps of the remaining SI region, as had been done earlier for the lesser Galago, G. senegelensis (Sur et al., 1980). Comparative data on the relative and absolute expansion of the hand area (or areas) in cortex, relative to other body surfaces or to actual skin surface areas, provide another approach to the un- derstanding of how evolutionary changes in neural structure and function are reflected in increased behavioral capacity.

\section{Materials and Methods}

Subjects. Eight adult Galago garnetti served as subjects in these studies (Table 1). This is the same species used in our previous studies of SI and SII and referred to as Galago crassicaudatus (Carlson and Welt, 1980; Burton and Carlson, 1986). The species designation of the greater Galago has changed over the past decade. The two types, which in the past were separated on the subspecies level, are presently considered as separate species. Galago crassicaudatus now refers to what was previously called Galago crassicaudatus argentatus. What was in the past referred to as Galago crassicaudatus, the species of our past and current studies, is now referred to as Galago garnetti (Bearder, 1987). All subjects were captive born and were within the normal size range for their gender. Behavioral data were obtained from Galago in this study and compared to data on Macaca described in a previous publication (Carlson, 1984).

All five Saimiri were normal adults, tested on their right hand. The two Cebus were first trained as normal and tested on their right hand (Table 1); $\mathrm{Cb} 1$ was later retested on the right hand after a single unilateral lesion in the left hemisphere, and $\mathrm{Cb} 2$ was retested on the right hand following an area 1 lesion in the left hemisphere, and on the left hand following a similar lesion in the right hemisphere. The lesions (Cebusarea 1) are illustrated in Figure 13, and intended to approximate the pattern of cutaneous projection from the hand defined as "area 1" by electrophysiological criteria in Cebus albifrons by Felleman et al. (1983; see Fig. 2). These data are also compared to previously published behavioral data from Macaca (Carlson, 1984).

Behavioral techniques. These behavioral data were obtained using 
Table 1. Summary for the three primate species

\begin{tabular}{|c|c|c|c|c|c|c|}
\hline Species & Origin & Gender & Age & $\begin{array}{l}\text { Hand } \\
\text { tested }\end{array}$ & $\begin{array}{l}\text { Weight } \\
\text { (g) }\end{array}$ & $\begin{array}{l}\text { Lesioned } \\
\text { hemisphere }\end{array}$ \\
\hline \multicolumn{7}{|c|}{ Galago garnetti } \\
\hline Gcla & Captive born & Female & Adult & Right & 920 & None \\
\hline Grc3a & Captive horn & Male & Adult & Right & 1065 & None \\
\hline Gc4a & Captive born & Male & Adult & Right & 950 & None \\
\hline Gc5a & Captive born & Male & Adult & Right & 1100 & None \\
\hline Gc6a & Captive born & Male & Adult & Right & 790 & None \\
\hline Gc8a & Captive born & Male & Adult & Right & 940 & None \\
\hline Gc9a & Captive born & Male & Adult & Right & 915 & None \\
\hline $\mathrm{Gcl0a}$ & Captive born & Female & Adult & Right & 660 & None \\
\hline \multicolumn{7}{|c|}{ Cebus apella } \\
\hline Cbla & Captive born & Female & Adult & Right & 2335 & None \\
\hline Cblb & & & & Right & & Area 1, left \\
\hline $\mathrm{Cb} 2 \mathrm{a}$ & Captive born & Male & Juvenile & Right & 1765 & None \\
\hline $\mathrm{Cb} 2 \mathrm{~b}$ & & & & Right & & Area 1, left \\
\hline $\mathrm{Cb} 2 \mathrm{c}$ & & & & Left & & Area 1 , right \\
\hline \multicolumn{7}{|c|}{ Saimiri sciureus } \\
\hline Ssla & Wild born & Fcmalc & Adult & Right & 695 & None \\
\hline Ss $2 a$ & Wild born & Female & Adult & Right & 670 & None \\
\hline Ss $3 a$ & Captive born & Male & Old & Right & 1000 & None \\
\hline Ss $4 a$ & Captive born & Male & Adult & Right & 1050 & None \\
\hline Ss $5 \mathrm{a}$ & Wild born & Female & Adult & Right & 595 & None \\
\hline
\end{tabular}

techniques described in previous publications (Carlson, 1984, Carlson and Burton, 1988). Animals were tested in the dark, with a low-level "white noise" piped to the test chamber. Access to water was restricted during the week (except during testing), with subjects maintained at 90$100 \%$ of normal body weight. While in a primate restraint chair, they were presented a rotating carousel with 12 pairs of handles that differed cither in sizc (cross-scetional diameter) or texturc (covered with different grades of sandpaper). Size handles varied from the smallest handle of $7 \mathrm{~mm}$ diameter to 9,12 , and $18 \mathrm{~mm}$ in cross-sectional diameter. All texture handles were $14 \mathrm{~mm}$ in diameter and covered by different grades of aluminum oxide abrasive ( $3 \mathrm{M})$, from the smooth 320 grains/linear inch (gr/in) grade to increasingly rough grades of 120,80 and $40 \mathrm{gr} / \mathrm{in}$. All handles were $3.8 \mathrm{~cm}$ long. Each of the six size and six texture pairs are referred to as a "comparison" throughout the article.

During the training phase, an animal was first presented with only the smallest (and correct) handle of the initial three size comparisons, with no handle in the other position. This same $7-0 \mathrm{~mm}$ comparison was presented, as a correction procedure, if an animal responded below $60 \%$ on the easiest comparison. During the "acquisition" phase the animal was presented pairs of vertically mounted handles (one above the other). The smallest or smoothest of the pair was designated as "correct" and is identified as the first value of a pair (i.e., 7-18 mm or $320-40 \mathrm{gr} / \mathrm{in}$ ). To indicate a response the animal was required to pull forward on the handle to activate the microswitch attached to the lever on which it was mounted. Each single presentation of a comparison is referred to as a "trial." If a correct choice was made on a trial, the animal was reinforced by a small quantity of water delivered through a metal nipple mounted at mouth level on the chair. If an incorrect response was made, no fluid was delivered and a buzzer sounded briefly to indicate an error. After a response the carousel rotated to the next position to present the adjacent pair of handles. During the acquisition task, the animal was presented a series of 12 pairs of handles (of the same size or texture comparison), in which the "correct" handle was varied from the upper to lower position in a quasi-random order. If the animal performed correctly on $80 \%$ of the trials in a session (composed of at least 50 trials) it was given a more difficult comparison in the next daily session. If it performed at less than $60 \%$ correct for $2 \mathrm{~d}$ it was returned to an easier comparison for the next session and if between $60-80 \%$ correct it continued testing on the same comparison in the subsequent session. By such a procedure the six possible combinations of the four handles were presented in the order given in Figure 6 (order of testing).
During acquisition, two measures of learning efficiency were used: (1) the rate of learning, shown by the number of sessions required to reach the $80 \%$ correct criterion, and (2) the number of errors accumulated prior to reaching criterion on a comparison level. Total errors, not total trials, to criterion was used as the indicator of efficiency of acquisition in this and previous studies (Carlson, 1984; Carlson and Burton, 1988). If an animal performed at levcls approaching but not execeding the expect $80 \%$ criterion, or if criterion was reached early in a session, errors would accumulate at a lesser rate than total trials and thereby serve as a more sensitive accumulative measure of efficiency. If an animal failed to respond for at least 50 trials in a session, errors were included in the total for that comparison, but if the $80 \%$ correct criterion was achieved in less than 50 trials, it would not qualify as obtaining criterion. If the animal was returned to that comparison (as a correction procedure), errors made during those sessions were not counted toward error scores for the individual comparison or for the total errors to criterion. Total errors on size and texture acquisition tasks is the sum of errors required to reach criterion on each of the six individual comparisons, including comparisons on which criterion was not reached in at least 20 sessions. Some animals that failed to master the $320-120 \mathrm{gr} / \mathrm{in}$ comparison (in less than 20 sessions) were run on an intermediate-level comparison (320-100 gr/in) and errors to criterion on this task were included in total errors.

After being trained on the six combinations of the four handles during acquisition, the animal was tested on the ALLS task in which all six comparisons were presented together in the same session, as a measure of consistent performance on these previously learned discriminations. The animal was run for 120 trial sessions over 5 consecutive days on the ALLS task. Scores for individual animals consist of the average percentage correct over the five sessions on each individual comparison The average score for individuals on the ALLS task is an average for the six tasks and these averages for individual comparisons and for the total of the six comparisons in the ALLS task are compared both within and between species.

Statistical significance was determined by using the nonparametric Mann-Whitney rank sum test. One-tailed $t$ test was used when comparing the prosimian Galago to the anthropoids (Macaca, Saimiri, or Cebus) since they were expected to perform better than Galago on all measures. When comparing within the anthropoid sample a two-tailed $t$ test was used since no directionality could be assumed. Only those tests with 0.05 probabilities or less were considered signiticant, though those less than 0.075 are included in the tables. 
Surgical and recording procedures in Galago. Surgical and recording procedures were as described in Carlson and Welt (1980) and Burton and Carlson (1986). All procedures were performed under surgical levels of anesthesia. Premedication of $10 \mathrm{mg} / \mathrm{kg}$ of ketamine hydrochloride and $0.05 \mathrm{ml}$ of atropine sulfate (administered intramuscularly) was followed by $20 \mathrm{mg} / \mathrm{kg}$ sodium pentobarbital (administered intraperitoneally), with subsequent doses of $5 \mathrm{mg} / \mathrm{kg}$ given as needed. The cornea was covered with Lacrilube. To maintain normal body temperature, the animal was placed on a hot water pad with rectal probe to monitor temperature.

The head was held in a Kopf stereotaxic instrument. After a scalp incision, and retraction of atlached muscle, a large parietal bone lap was removed to expose the region of cortex between the rectus and intraparietal and from the midline to the lateral sulcus (Fig. 3). Prior to opening the dura, a shallow chamber of dental acrylic was attached to the skull margins to contain a pool of sterile silicone fluid (Dow Chemical) over the exposed cortex. The dura was opened and the cortical surface was photographed to provide vascular landmarks for placement of electrode penetrations.

I ow-impedance tungsten microelectrodes (1.0-1.5 M 2 at $1000 \mathrm{~Hz}$ ) were lowered $800-1200 \mu \mathrm{m}$ into the parietal region as the face, arm, and leg were briskly stimulated. When evoked activity was detected, receptive fields were defined by small probes to localize minimal receptive field to brushing or to punctate stimuli. Following complete exploration of the parietal cortex, the animal was anesthetized with a lethal dose of sodium pentobarbital. When spontaneous respiration ceased, it was perfused intracardially with $0.9 \%$ saline followed by $10 \%$ neutral buffered formalin-saline for histological processing of the cortex.

Cortical lesions in Cebus. Sterile surgical procedures were followed throughout, with the animals kept at surgical levels of anesthesia as described above. The scalp was shaved and scrubbed with Septisol, 70\% alcohol, and $10 \%$ Betadine solutions. The scalp was incised from the brow to the occiput with the head held in the stereotaxic instrument. Skin margins were retracted and covered with damp saline-soaked sponges and a large skull flap was removed from over parietal cortex. The dura was opened laterally near the skull edges to expose the primary somatic sensory region, indicated by the configuration of the central and lateral sulci (Fig. 4).

Electrophysiological criteria were used to locate the hand area. Responses of cell clusters were recorded with sterile microelectrodes lowered $800-1200 \mu \mathrm{m}$ into the parietal region over the expanse of the postcentral crown and 1-2 $\mathrm{mm}$ into the central sulcus. The active sites were noted on drawings of the cortical vasculature, to delineate the extent of area 1 corresponding to the distal to proximal sequence of receptive fields found in a posterior to anterior axis of the postcentral gyrus (Felleman et al., 1983). Cortical lesions were made by subpial aspiration of the gray matter through a 16 gauge suction tube. After filling the lesion site with an absorbable gelatin sponge (GelFoam), the dura was repositioned and sutured with 4-0 coated Vicryl and covered with gelatin film (GelFilm). Small holes were drilled into the bone flap and skull margins, the flap was then reinserted and stabilized with Vicryl sutures. Connective tissue was sutured with absorbable sutures and the scalp closed with interrupted 4.0 silk sutures, which were removed 5$7 \mathrm{~d}$ later. The animal's temperature and vital signs were monitored until recovery from anesthesia was complete. Prophylactic administration of antibiotic Combi-Pen $(0.25 \mathrm{ml} / \mathrm{kg})$ was given in a single dose. A 1-2 week recovery period followed before tactile discrimination tasks were initiated. After completion of behavioral testing, the animal was killed and the brain prepared for histological processing.

Histological processing and computer reconstruction of cortex. Cortical blocks through the pre- and postcentral gyrus were cut in $50 \mu \mathrm{m}$ sections in the sagittal plane and stained for Nissl substance with cresylecht violet. Every 10th section was drawn with a camera lucida, and the drawings were digitized. Computer reconstructions of the drawings and of the estimated area of cortical removal are shown in Figure 13. Threedimensional reconstructions of the lesions and remaining postcentral gyrus were obtained by outlining a contour from the remaining crown to the anterior bank of the gyrus of each section. Other details in the drawings include layer VI, layer IV, and the precentral gyrus. The full mediolateral profile of the lesion was created by the computer based on the magnification factor of the drawing, the thickness of sections, the interval between sections, and the viewing angle specified by the $x, y, z-$ coordinates of the three-dimensional image. The illustrated profile was chosen to best visualize the full mediolateral expanse of the removal.

Measurement of skin area and cortical projection area of glabrous hand and foot. Three of the behavioral animals (Gc5, Gc8, and Gclo) were among the 12 adult Galago used to determine the surface area of the glabrous hand and feet by direct carbon powder prints (PhillipsConroy et al., 1986). Two juvenile male Macaca mulatta were used for the hand and foot prints (and from enlarged photographs of the hand in an additional juvenile) to determine the surface of the glabrous skin. To obtain the direct hand and foot prints, animals were tranquilized with a single dose of ketamine hydrochloride $(10 \mathrm{mg} / \mathrm{kg})$ and atropine sulfate $(0.05 \mathrm{ml})$ administered intramuscularly. Glabrous surfaces were cleaned and dried prior to the dusting of carbon powder. With the digits spread apart, the hand or foot was flattened against 5 inch wide cellophane tape (book tape, $3 \mathrm{M}$ ) and pressed firmly against the tape to leave a complete impression of the glabrous print. The tape was fixed to plain white paper for preservation. From photocopies of hand and foot prints (or of hand photographs) outlines of the glabrous surface were traced on a digitizing pad and the area of each digital, palmar, or volar surface was calculated.

The SI surface areas for the hand, foot, and other body areas in Galago were calculated by digitizing the outline of the complete SI maps obtained in this study (Gc5-83, Gc6-84, Gc7-84) and from our maps of the SI hand area in a previous publication (146-77, 333-73; Carlson and Welt, 1980). From our previous publication of Galago SII, estimates of the size of the hand and foot areas were obtained from animals G2 and G3 (Burton and Carlson, 1986). Maps of SI in Macaca mulatta were obtained from the published figures of Paul et al. (1972) and for Macaca fascicularis from Nelson et al. (1980). Estimates of the hand and foot areas in SII of Macaca were taken from published figures in Friedman et al. (1986) and Robinson and Burton (1980).

Direct prints of the skin surfaces of the hand and foot in five Saimiri and four Cebus (including two adult animals not used for behavioral testing) were digitized as for the other species. Measurements of the SI surface of the hand and foot areas were obtained from previously published maps of Saimiri (Sur et al., 1982) and Cebus (Felleman et al., 1983). At least three measurements were made of hand and foot projection areas, with an average value calculated in SI (and SII in Galago and $\mathrm{Macaca}$ ) in each species.

\section{Results}

\section{Galago and Macaca}

\section{Size discrimination}

Size acquisition. Seven adult Galago were initially trained to the $80 \%$ correct criterion on the six size acquisition comparisons, followed by five sessions on the size ALLS task. The acquisition profiles of individual animals on the first three size comparisons, shown as percentage correct for each comparison on each session, are illustrated in Figure 5. By reference to Table 2 , it is possible to characterize both the individual ( $\mathrm{Gcl}-\mathrm{Gc} 9$ ) and the species average ( $\mathrm{Gc}$ AVG and Mm AVG) error scores.

As a group Galago required two or three sessions on each of the first two tasks, the easy $(7-18 \mathrm{~mm})$ and moderate $(7-12 \mathrm{~mm})$ level comparisons. On the third and least discrepant (defined by absolute physical difference between handles, 7-9 $\mathrm{mm}$ comparison, i.e., $2 \mathrm{~mm}$ difference), two to seven sessions were required to reach criterion (Fig. 5). When error scores on individual size comparisons for Galago were compared to those for Macaca, Galago was found to make significantly more errors on the first three tasks in order of testing and on the total over all six comparisons (Table 2, top; Fig. 6).

Size ALLS. Following the acquisition task, all animals were tested on the ALLS task. The level of performance on the ALLS task is shown as percentage correct for the six comparisons averaged over the five sessions (Table 2, bottom; Fig. 6, right). On average Galago attained above $90 \%$ on the two easy (7-18 $\mathrm{mm}, 9-18 \mathrm{~mm})$ and two moderate $(12-18 \mathrm{~mm}, 7-12 \mathrm{~mm})$ level tasks. They performed over $80 \%$ on one difficult $(9-12 \mathrm{~mm})$, but under $60 \%$ correct of the most difficult (7-9 mm), comparison. The efficiency of acquisition for Galago was significantly 


\section{SIZE ACQUISITION}

Figure 5. The course of acquisition for size tasks by normal Galago garnetti is shown for Gc1, Gc3-Gc6, Gc8, and Gc9. See Carlson (1984) for normal Macaca mulatta. These data show the percentage correct on the discrimination of the cross-sectional diameter of handles by each animal over individual sessions on the first three size comparisons in the order of testing. Weeks of testing indicates the length of time an animal was tested on size acquisition.
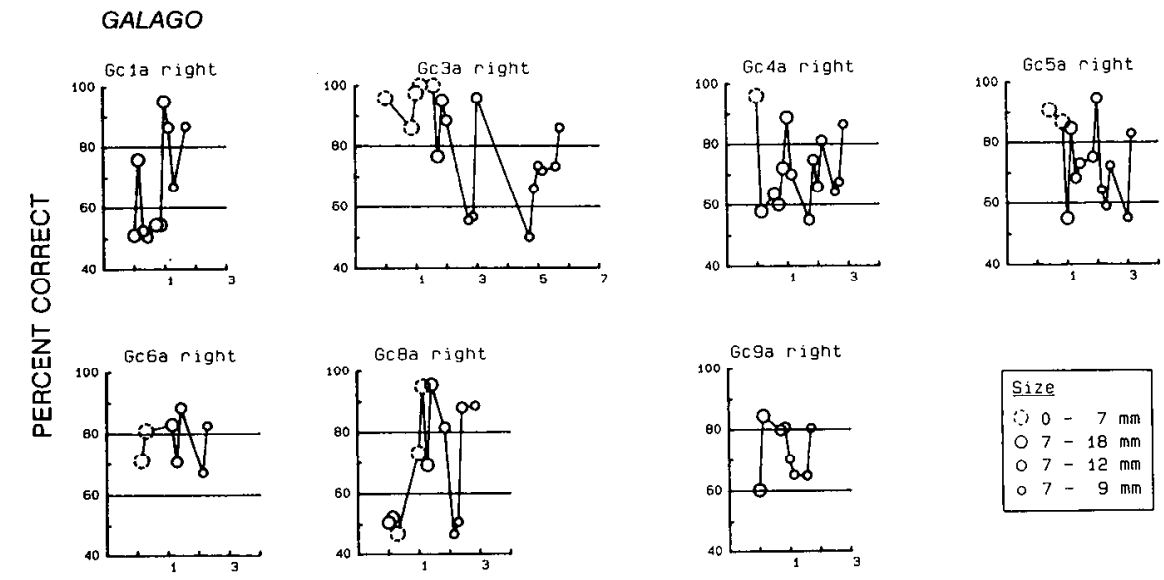

WEEKS OF TESTING worse than that of Macaca on the first three tasks in order of testing and on the total errors over the six tasks, but when the error scores were ranked by order of difficulty (defined by physical differences between the handles) rather than order of testing, the combined contribution of these factors to errors scores can be appreciated (Fig. 6). On the size ALLS task there was no contribution of "order of testing" as the same six comparisons were presented together repeatedly in the same session. On the ALLS task where "order of difficulty" was the remaining influence on performance, Galago was significantly inferior to $\mathrm{Ma}$ caca only on the difficult 7-9 mm comparison.

\section{Texture discrimination}

Texture acquisition. Following completion of the size discrimination tasks, the same seven Galago and one additional animal ( $\mathrm{Gc} 10$ ) were trained to discriminate between a series of six texture comparisons. The acquisition profiles for the first three comparisons are illustrated in Figure 7. On average Galago required about six sessions to reach criterion on the first and easy task (320-40 gr/in, $386 \mu \mathrm{m}$ difference in grain size) and averaged more than 200 errors prior to criterion (Table 3 , top). On the second task (320-80 gr/in), three or four sessions were required and only 65 errors on average were made prior to criterion. The third task (320-120 gr/in and $91 \mu \mathrm{m}$ grain difference) was the second most discrepant in terms of grain size but consistently the most difficult in terms of errors to criterion for both species. On this task, two Galago ( $\mathrm{Gc} 9$ and $\mathrm{Gc} 10$ ) failed to reach criterion after more than 40 sessions but mastered an easier (320-100 gr/in) comparison in only four sessions (Fig. 7). When tested further on the more difficult discrimination (320$120 \mathrm{gr} / \mathrm{in}$ ), they once again failed, whereas the six animals that reached criterion made an average of 766.8 errors.

As a group Galago made significantly more errors than $\mathrm{Ma}$ caca on the first (320-40 gr/in), second (320-80 gr/in), and third (320-120 gr/in) texture acquisition tasks in order of testing (Fig. 8 ), yet these differences do not reflect entirely the order of difficulty as no significant difference was found on the 120-80 gr/ in (52 $\mu \mathrm{m}$ difference) comparison. Significant group differences were obtained on total errors over all 6 tasks (Table 3, top; Fig. $8)$.

Texture ALLS. Following the acquisition task, seven of the original animals were tested on texture ALLS task. On average Galago scored over $90 \%$ correct on the easy and over $80 \%$ correct on the moderate level tasks. On the difficult 320-120
Figure 6. The bar graphs illustrate the average number of errors made during size acquisition and ALLS performance tasks, prior to reaching the $80 \%$ correct criterion for Galago (see Table 2) and Macaca (see Carlson, 1984). The accumulated errors for the two species on the different size tasks are given both in the order of testing and when rearranged by order of difficulty (difficulty being a physical, but not necessarily the psychological, difference between handles). The ALLS performance data are presented as average percentage correct for individual comparisons by order of difficulty. The asterisks found over some bars indicate significant differences (Mann-Whitney one-tailed tests; *, $p \leqq$ $0.05 ;^{* *}, p \leqq 0.01 ;{ }^{* * *}, p, \leqq 0.001$; see Materials and Methods).

\section{SIZE ACQUISITION}

ORDER OF TESTING

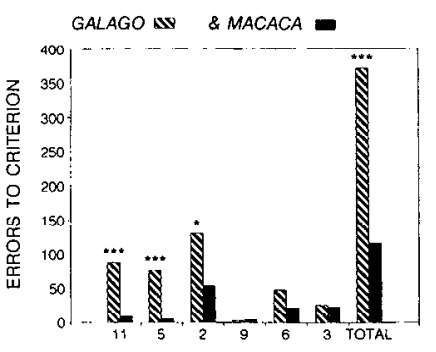

SIZE DIFFERENCES (in $\mathrm{mm}$ )
SIZE ALLS

URDER OF DIFFICULTY

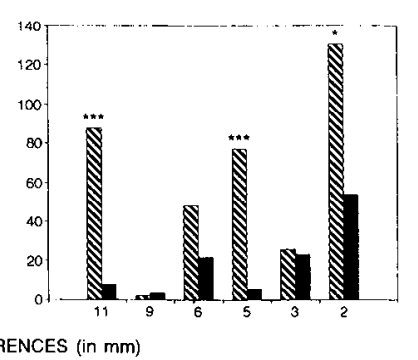

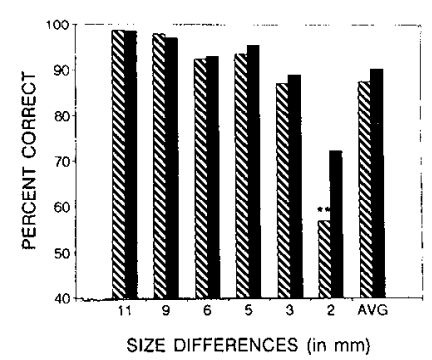


Table 2. Size discrimination by Galago (in order of difficulty)

\begin{tabular}{|c|c|c|c|c|c|c|c|c|}
\hline & \multicolumn{6}{|c|}{ Size comparison (difference) } & \multirow[b]{2}{*}{ Total } & \multirow[b]{2}{*}{ Average } \\
\hline & $\begin{array}{l}7-18 \\
\mathrm{~mm} \\
(11 \mathrm{~mm})\end{array}$ & $\begin{array}{l}9-18 \\
\mathrm{~mm} \\
(9 \mathrm{~mm})\end{array}$ & $\begin{array}{l}12-18 \\
\mathrm{~mm} \\
(6 \mathrm{~mm})\end{array}$ & $\begin{array}{l}7-12 \\
\mathrm{~mm} \\
(5 \mathrm{~mm})\end{array}$ & $\begin{array}{l}9-12 \\
\mathrm{~mm} \\
(3 \mathrm{~mm})\end{array}$ & $\begin{array}{l}7-9 \\
\mathrm{~mm} \\
(2 \mathrm{~mm})\end{array}$ & & \\
\hline \multicolumn{9}{|c|}{ Errors to criterion on size acquisition task } \\
\hline $\mathrm{Gc1}$ & 239 & 1 & 64 & 174 & 34 & 81 & 593 & - \\
\hline Gc3 & 33 & 0 & 3 & 14 & 20 & 321 & 391 & - \\
\hline Gc4 & 129 & 0 & 73 & 173 & 17 & 86 & 478 & - \\
\hline Gc5 & 50 & 0 & 0 & 96 & 2 & 190 & 338 & - \\
\hline Ge6 & 28 & 6 & 69 & 44 & 68 & 60 & 275 & - \\
\hline Gc8 & 89 & 1 & 10 & 10 & 9 & 72 & 191 & - \\
\hline $\mathrm{Gc} 9$ & 44 & 6 & 119 & 29 & 31 & 103 & 332 & - \\
\hline Gc AVG & 87.4 & 2 & 48.3 & 77.1 & 25.9 & 130.4 & 371.1 & - \\
\hline Mm AVG & 7.8 & 3.3 & 21.6 & 5.2 & 23.2 & 54 & 115.1 & - \\
\hline$p$ & $0.0003^{* * *}$ & NS & NS & $0.0006^{* * *}$ & NS & $0.028^{*}$ & $0.001^{* * *}$ & - \\
\hline \multicolumn{9}{|c|}{ Percentage correct on size ALLS task } \\
\hline $\mathrm{Gcl}$ & 100 & 97.5 & 97.44 & 97.37 & 92.11 & 71.79 & - & 92.67 \\
\hline Gc3 & 100 & 100 & 91 & 89 & 78.79 & 55 & - & 85.64 \\
\hline Gc4 & 100 & 100 & 97.98 & 97 & 89 & 58 & - & 90.32 \\
\hline Gc5 & 100 & 100 & 94.87 & 98.67 & 96.05 & 53.95 & - & 90.57 \\
\hline Gc6 & 96.7 & 98.89 & 92.13 & 90.22 & 80.9 & 49.45 & - & 84.69 \\
\hline Gc8 & 96.55 & 91.38 & 80.7 & 91.23 & 82.76 & 54.39 & - & 82.9 \\
\hline $\mathrm{Gc} 9$ & 96.88 & 96.92 & 93.44 & 90.91 & 90.63 & 56.72 & - & 87.34 \\
\hline Gc AVG & 98.5 & 97.8 & 92.5 & 93.5 & 87.2 & 57 & - & 87.7 \\
\hline $\mathrm{Mm}$ AVG & 98.5 & 97 & 93.1 & 95.5 & 89.1 & 72.4 & - & 90.5 \\
\hline$p$ & NS & NS & NS & NS & NS & $0.0017^{* *}$ & - & NS \\
\hline
\end{tabular}

${ }^{*}, p \leqq 0.05 ;{ }^{* *}, p \leqq 0.01 ;{ }^{* * *}, p \leqq 0.001$.

gr/in task (composed of smaller grain sizes but with greater grain size difference, i.e., $91 \mu \mathrm{m}$ difference), they performed under $60 \%$ correct compared to the $120-80 \mathrm{gr} /$ in comparison $(52 \mu \mathrm{m}$ difference), on which they averaged over $70 \%$ (Table 3, bottom; Fig. 8). Although six of the eight Galago reached the $80 \%$ criterion on the $320-120 \mathrm{gr} /$ in during acquisition, none performed over $60 \%$ on that comparison on average over the five ALLS sessions. Galago consistently performed below Macaca on all six texture comparisons. Statistical comparison of Galago and Macaca performance revealed significant differences on four of six individual comparisons (including the three most difficult tasks) and on the average over the six comparisons (Table 3, bottom).

\section{Microelectrode mapping of the SI head, trunk, leg, and foot areas}

A composite obtained from the three animals mapped in this study, combined with highly detailed hand maps from two animals in the previous study (Carlson and Welt, 1980), is given in Figure $9 A$. Within each of the projection areas for the different body surfaces, the progression of RFs was highly consistent from one animal to the next and to those progressions seen in $G$. senegelensis (Sur et al., 1980). As shown in Figure 9 $B$, the posterior portion of the head and ear projects to the posterior region of the SI head arca, with the cyc, snout, and nosc cach projecting more anteriorly. Fields on the glabrous and hairy hand were intermediate to a split arm area as seen in Figure $9 B$ but RFs on the hand were not extensively examined in these studies. From a row of penetrations extending from lateral to medial SI, RFs progressed from the glabrous hand to fields on the ventral and dorsal arm and then to the trunk, leg, arid foot.
The organization of the foot area resembled that described earlier for the hand, with RFs on the dorsal and ventral digit tips located at the anterior border and fields on the proximal digits and plantar surfaces intermediate to those on the dorsal, hairy surface of the hand and foot. In spite of the major size differences between the greater Galago, G. garnetti (average 1000 $\mathrm{gm}$ ), and the lesser Galago, G. senegelensis (average $250 \mathrm{gm}$; Sur et al., 1980), the relative proportion of SI devoted to the different body surfaces, and the general topographic details were highly similar in the two prosimian species.

\section{Glabrous hand and foot area and SI and SII magnification factors for Galago and Macaca}

From enlarged photographs of individual body parts of an adult Galago, it was determined that the head represented approximately $11.4 \%$ of the body surface. In our recent complete maps of SI, we found that the head projected to $37 \%$ of the total SI area - a threefold increase in the relative representation. Similarly, the skin surface of the glabrous hand represented only $2 \%$ of the total body surface area but the cortical projection area for the hand represented $11.2 \%$ of the total SI area. This represents more than a fivefold elaboration of cortical surface as compared to the skin surface. The skin of the glabrous foot represented $3.1 \%$ of body surface area and $8.7 \%$ of total SI surface area, less of an elaboration than for the glabrous hand. In addition, the area of glabrous skin on the hands and feet was estimated from direct prints of 12 adult Galago and 2 juvenile M. mulatta (and photographs of another Macaca) chosen to approximate the size of animals used in previous electrophysiological recording experiments (Paul et al., 1972; Nelson et al., 


\section{TEXTURE ACQUISITION}

Figure 7. The course of acquisition for texture tasks by normal Galago $\mathrm{Gcl}$, Gc3-Gc6, and Gc8-Gc10 is shown. These data show the percentage correct on the discrimination of the different grades of sandpaper-covered handles by individual animals on all sessions on the first three texture comparisons in the order of testing. Weeks of testing is in reference to the first day of size acquisition training.
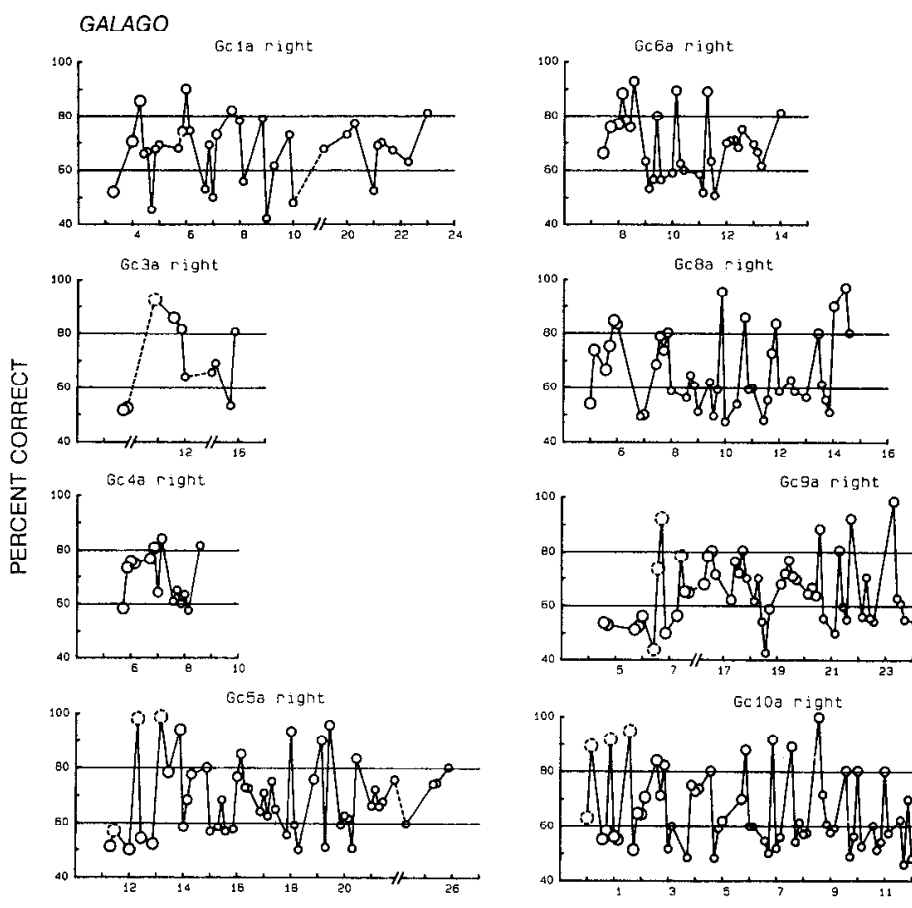

$\Rightarrow 0-320$ gr/in

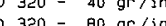
$320-120$ gr/in $320 \quad 100 \mathrm{gr} / \mathrm{in}$
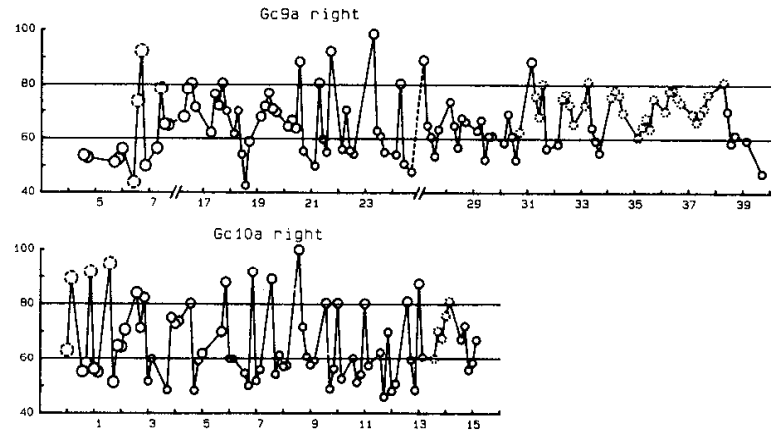

WEEKS OF TESTING

Table 3. Texture discrimination by Galago (in order of difficulty)

Sizc comparison (difference)

$320-40 \mathrm{gr} / \mathrm{in} . \quad 120-40 \mathrm{gr} / \mathrm{in} . \quad 80-40 \mathrm{gr} / \mathrm{in} . \quad 320-80 \mathrm{gr} / \mathrm{in} . \quad 320-120 \mathrm{gr} / \mathrm{in} . \quad 120-80 \mathrm{gr} / \mathrm{in}$.

$(386 \mu \mathrm{m}) \quad(295 \mu \mathrm{m}) \quad(243 \mu \mathrm{m}) \quad(143 \mu \mathrm{m}) \quad(91 \mu \mathrm{m})$

Average

Errors to criterion on texture acquisition task

$\begin{array}{lcrrr}\text { Gc1 } & 174 & 39 & 59 \\ \text { Gc3 } & 125 & 9 & 22 & \\ \text { Gc4 } & 192 & 20 & 520 & \\ \text { Gc5 } & 285 & 2 & 7 & 139 \\ \text { Gc6 } & 87 & 3 & 3 & \\ \text { Gc8 } & 89 & 4 & 18 & \\ \text { Gc9 } & 490 & 6 & 12 & 147 \\ \text { Gc10 } & 374 & 11 & 75 & \\ \text { Gc AVG } & 227 & 11.8 & 89.5 \\ \text { Mm AVG } & 77.2 & 5.2 & 11.3 \\ p & 0.0043^{* *} & 0.0566 & \mathrm{NS}\end{array}$

Percentage correct on texture ALLS task

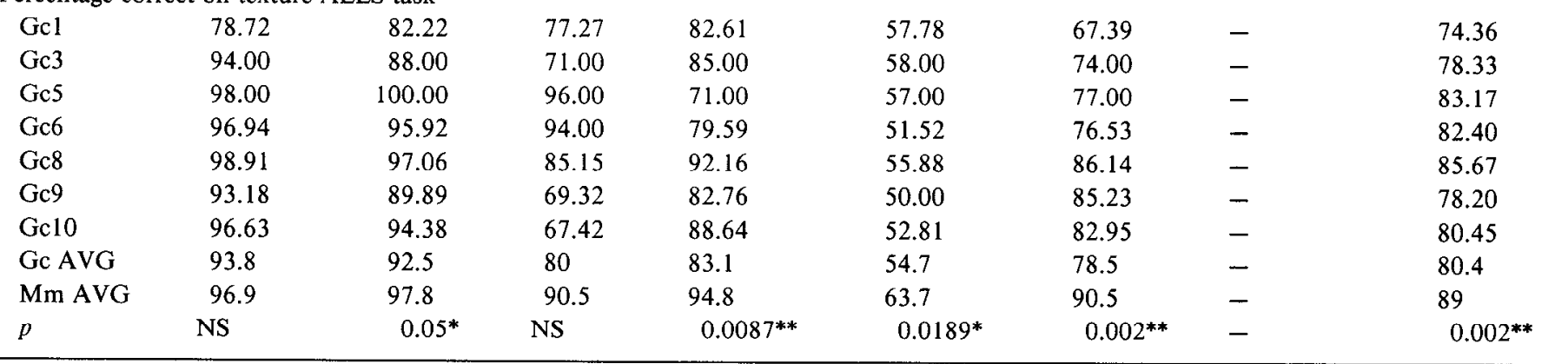

${ }^{a}$ Failed to reach criterion in $<30$ sessions.

$*, p \leqq 0.05 ; * *, p \leqq 0.01 ; * * *, p \leqq 0.001$. 
TEXTURE ACQUISITION

ORDER OF TESTING

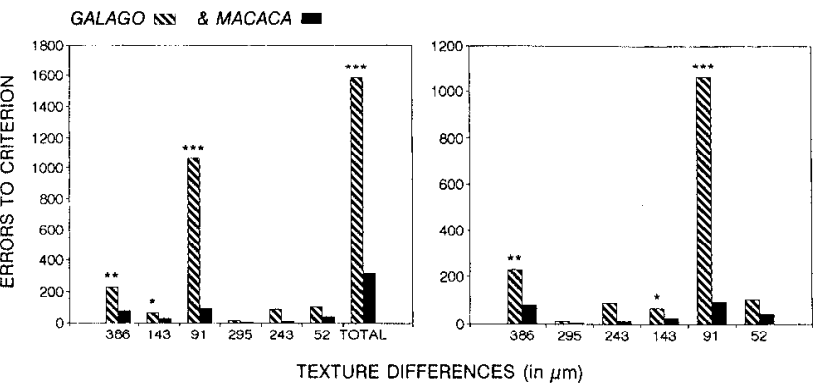

1980). The average of these measures, along with body weight for cach specics, is given in Tablc 4.

For Galago the skin area of the glabrous hand was $73 \%$ of the skin area for the foot area, yet the hand projection area in

\section{TEXTURE ALLS}

ORDER OF DIFFICULTY

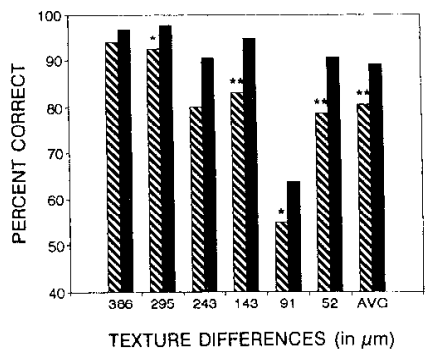

Figure 8. The bar graphs illustrate the average number of errors made during texture acquisition and ALLS performance tasks, for Galago (see Table 3) and Macaca (see Carlson, 1984). The accumulated errors for the two species on the different texture tasks are given in the order in which they were presented (order of testing) and in order of difficulty. See Figure 6 for additional details.
A.
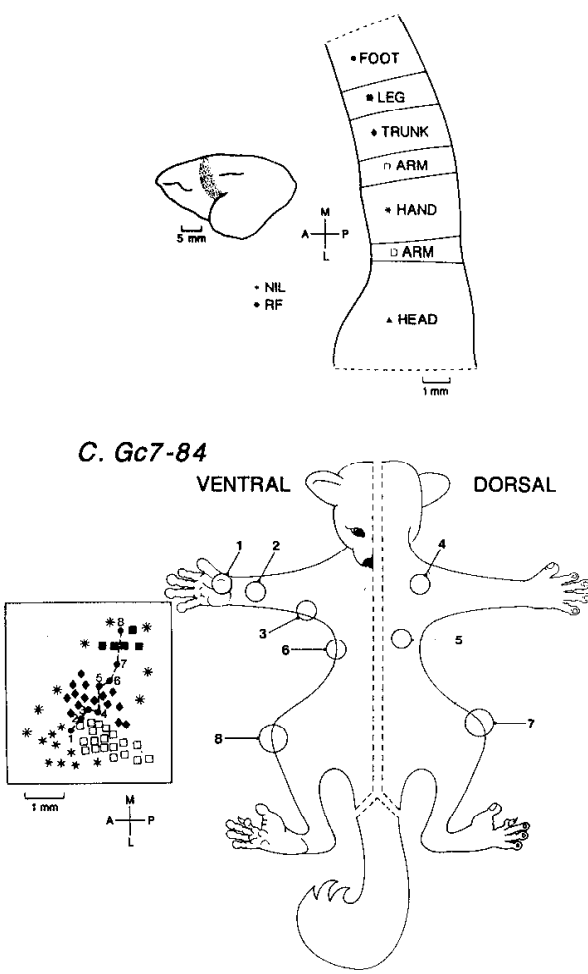

B. Gc5-83
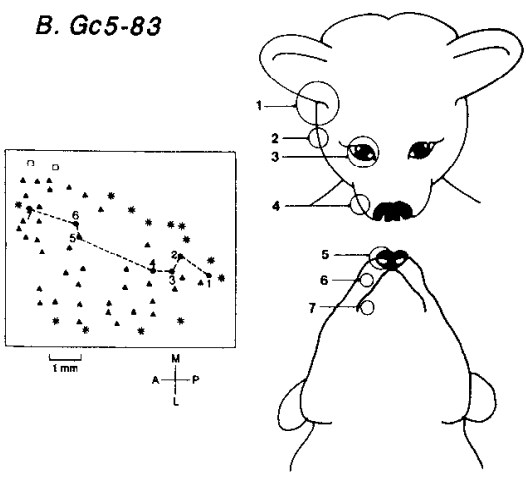

D. Gc6-84
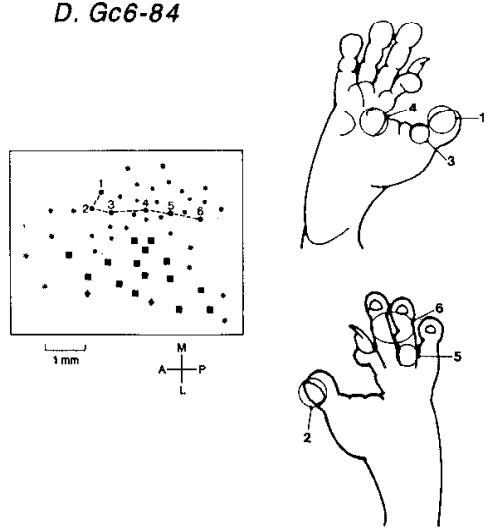

Figure 9. Stylized map of the entire body area $(A)$, head $(B)$, trunk $(C)$, and foot $(D)$ areas in SI of $G$. garnetti. These are microelectrode maps of the entire medial $(M)$ to lateral $(L)$ and anterior $(A)$ to posterior $(P)$ extent of the projection of glabrous and hairy body surfaces to SI. $A$, The summary drawing of the maps of three animals from the present study (Gc5-83, Gc6-84, and Gc7-84) and two animals (146-77, 333-73) from a previous study of the SI hand area (Carlson and Welt, 1980) were used to construct the composite and individual maps illustrated. These same maps were used to determine the individual SI areas for the hand and foot given in Table 4. The drawing of the lateral view of the left hemisphere includes a stippled region indicating the general location of the SI body map, between the sagittally oriented sulci in the frontal and posterior parietal regions (see Fig. 3 for more details). The symbols used to denote receptive fields $(R F)$ from specific body parts are shown in the expanded SI map summary. The RFs illustrated in $B-D$ are designated by the large solid circles and the NIL (no response) recording sites are represented by the asterisks, as shown in $A$. B, In Gc5-83, a posterior-anterior progression of recording sites in the most lateral region of SI is associated with RFs beginning at the ear, moving to the eye, snout, nose, upper lip, and chin. This pattern of subdivisions in the SI head (solid triangles) area in $G$. garnetti is similar to that in $G$. senegelensis (Sur et al., 1980). C, A lateral-medial progression of RFs through the middle region of SI illustrates the progression from the glabrous hand (see Carlson and Welt, 1980), to ventral and dorsal arm (open squares), and finally dorsal and ventral trunk (solid diamonds) and leg (solid squares). The six-pointed stars designate RFs on the hand and the asterisks indicate NIL recording sites. D, An anterior-posterior series of penetrations (in Gc6-84) illustrate an RF sequence through the foot area beginning medially on the glabrous tip of D1, moving to the nail and to proximal fields on the volar surface. Finally, in the most posterior region RFs on the distal, then proximal, hairy surface of the digits are found. The small circles indicate RFs on the foot. 
Table 4. Cortical magnification factors for SI and SII

\begin{tabular}{|c|c|c|c|c|c|}
\hline & $\begin{array}{l}\text { Skin area } \\
\left(\mathrm{mm}^{2}\right)\end{array}$ & $\begin{array}{l}\text { SI area } \\
\left(\mathrm{mm}^{2}\right)\end{array}$ & $\begin{array}{l}\text { Mag } \\
\left(10^{-3}\right)\end{array}$ & $\begin{array}{l}\text { SII area } \\
\left(\mathrm{mm}^{2}\right)\end{array}$ & $\begin{array}{l}\mathrm{Mag} \\
\left(10^{-3}\right)\end{array}$ \\
\hline \multicolumn{6}{|c|}{ Galago garnetti } \\
\hline $\mathrm{G}$ hand & $1215.63^{a}$ & $5.6^{b}$ & $(4.61)$ & $2.9^{c}$ & (2.39) \\
\hline$G$ foot & $1517.43^{a}$ & $4.1^{b}$ & $(2.71)$ & $0.4^{c}$ & $(0.26)$ \\
\hline Weight & $967.5^{a}$ & & & & \\
\hline \multicolumn{6}{|c|}{ Macaca mulatta } \\
\hline G hand & $2812.54^{d}$ & $44^{\circ}$ & $(15.64)$ & 35 & $(12.44)$ \\
\hline$G$ foot & $4365.17^{d}$ & $21^{\circ}$ & $(4.81)$ & $5.5^{\prime}$ & $(1.26)$ \\
\hline Weight & $3500^{d}$ & & & & \\
\hline
\end{tabular}

"Average of 12 adult Galago.

${ }^{\circ}$ From Gc7-84, Gc6-84, and Carlson and Welt (1980).

"From Burton and Carlson (1986).

"From three juvenile Macaca mulatta.

"From Paul et al. (1972).

'From Robinson and Burton (1980).

was for SI hand and the smallest magnification factor was for SII foot.

For Macaca, a similar pattern was seen for the glabrou's skin of hand and foot and cortical areas. However, the absolute skin and cortical arcas and cortcx/skin ratios werc all larger than for Galago. The actual skin area of the surface of the glabrous hand in Macaca was only $63 \%$ of the skin area of the foot, yet the SI projection of the glabrous hand to SI (areas $3 \mathrm{~b}$ and I) was about six to seven times that of the foot. By contrast, the absolute size of the SII hand area was about $80 \%$ that of the SI hand area, rather than $50 \%$ as in Galago. In both species the actual skin area of the foot exceeded that of the hand but cortical projections area of hand areas to SI and SII were larger than for the foot. The cortical magnification factor for SI and SII hand areas for Macaca was four to five times greater than for Galago. This indicates that the projection of cutaneous input from the hand to the two major cortical areas necessary for normal tactile function is vastly expanded in Macaca relative to Galago, as well as being organized into a more complicated topographic pattern across areas $3 b$ and 1 .

\section{Saimiri and Cebus}

\section{Size discrimination, Saimiri}

Size acquisition. The percentage of correct resporises for each session and the number of sessions required to reach criterion on the first three size acquisition tasks is illustrated as acquisition curves (Fig. 10). Comparison of errors to criterion for Saimiri and Galago indicates a similar efficiency of acquisition. However, when compared to Macaca, Saimiri made significantly more errors on the three first tasks (order of testing, not order of difficulty) and for the total of the six comparisons (see Table 5, top; Figs. 11 $A, 12 A$ ).

Size ALLS. On average all Saimiri, except for Ss3, scored above $80 \%$ correct across the six comparisons (Table 5 , bottom). The average error scores on the size ALLS task for Saimiri and Galago were not significantly different, but on the difficult 7-9 mm comparison, Saimiri scored significantly better than Galago (Fig. 11A). Although Saimiri showed significantly lower efficiency of acquisition compared to Macaca, this did not carry over to the performance on the size ALLS task. There was no

\section{SIZE ACQUISITION}

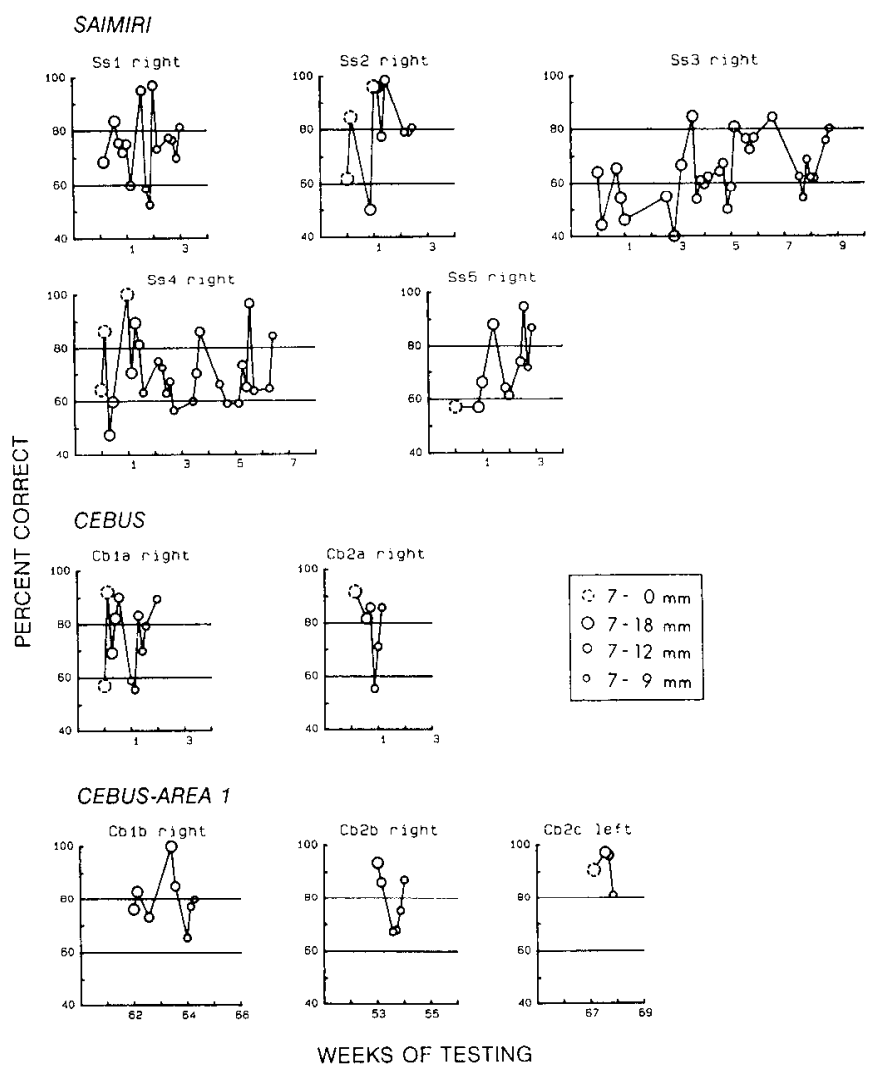

Figure 10. Individual size acquisition profiles for normal Saimiri (Ss 1$S s 5)$ are shown at the top, normal Cebus $(C b 1 a, C b 2 a)$ in the middle, and Cebus-area-1 $(C b I b, C b 2 b / c)$ at the bottom. Only the first three tasks presented in order of testing are illustrated. See Figure 5 for more detail.

significant difference between the two species overall or for any of the individual size comparisons on the ALLS task.

\section{Size discrimination, Cebus}

Size acquisition. The two Cebus (Cb1a, Cb2a) were initially trained as normal animals on the size discrimination tasks. The percentage correct for the individual animals is illustrated in Figure 10 and errors to criterion are presented in Table 6 (top). No significant difference in the overall learning efficiency was evident (but Cebus made roughly half the total number of errors over all six comparisons as Galago), except for the 7-12 mm comparison where Cebus made many fewer errors than Galago $(p=0.056$; Fig. $11 B)$. Compared to Macaca, Cebus acquired the size discriminations with less overall efficiency (Cebus made twice the total number of errors over all six comparisons as Galago), but no statistical differences on individual comparisons or total errors were detected (Table 6, top). The small sample size for Cebus $(n=2)$ may have contributed toward the lack of statistical significance.

Size ALLS. The percentage correct for the two normal Cebus on the size ALLS task is shown in Table 6 (bottom). Cebus and Galago showed the same performance ability on size tasks, with no significant species difference. Saimiri performed on average about $7 \%$ above Galago and about $7 \%$ lower than Macaca on the difficult size comparisons, but no statistical differences were 
SIZE ACQUISITION

ORDER OF TESTING
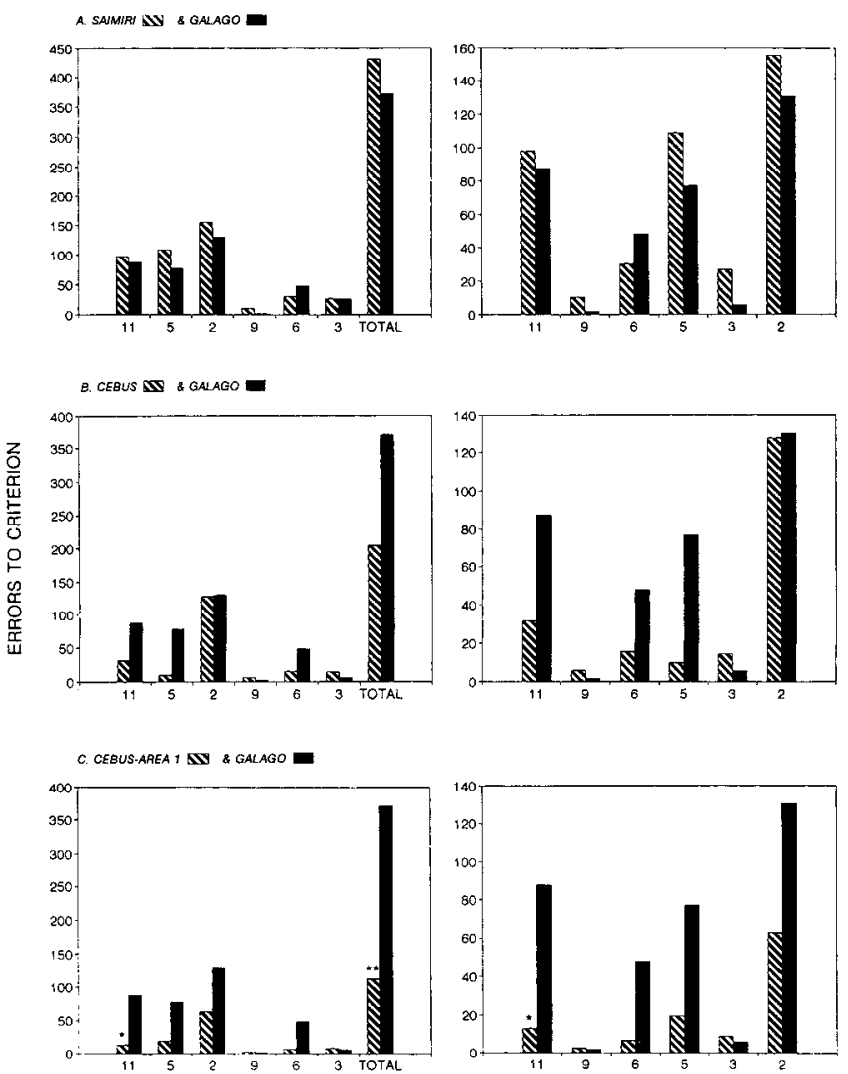

SIZE DIFFERENCES (in mm)

\section{SIZE ALLS}

ORDER OF DIFFICULTY
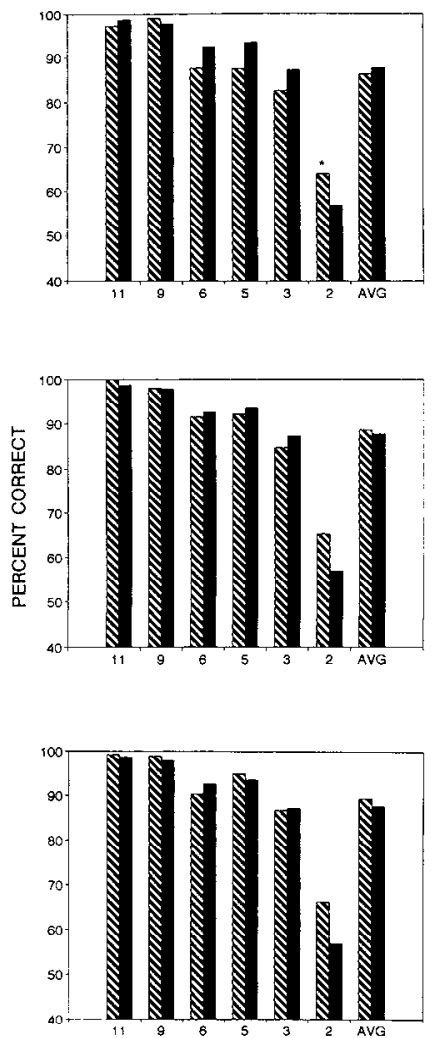

SIZE DIFFERENCES (in mm)
Figure 11. Bar graphs show the average number of errors made during size acquisition and ALLS performance tasks, comparing Galago to Saimiri $(A)$, Cebus $(B)$, and Cebus-area $1(C)$. See Figure 6 for more detail found between species either on individual comparisons or over all six comparisons (see Table 6, bottom; Figs. 11B, 12B).

Although statistical comparisons were not made between $\mathrm{Sai}$ miri and Cebus because of the small number of animals in each group, it is possible to rank species by total errors to criterion during acquisition and average performance on the ALLS task. Over the course of size acquisition, species differed by approximately 100 total errors, with Saimiri showing the most errors, followed by Galago, Cebus, and Macaca (see Tables 5A,6A). The same ranking is seen for size ALLS performance.

\section{Size discrimination, Cebus-area 1}

Size acquisition. A comparison of the acquisition profiles for the two Cebus before and after lesions shows fewer sessions were required to criterion postoperatively on the first three comparisons (Fig. 10). Postoperative error scores for Cebus-area 1 (on the hand contralateral to the area 1 lesion) were half those made on the same hand prior to the lesions. When $\mathrm{Cbl}$ was tested on the previously trained right hand after a left hemisphere lesion $(\mathrm{Cb} / \mathrm{b})$, it made half the number of errors as during original learning ( $\mathrm{Cb} 1 \mathrm{a})$. Whereas $\mathrm{Cb} 2$ made about the same number of errors postoperatively as preoperatively on the previously trained right hand $(\mathrm{Cb} 2 \mathrm{~b})$, following a left hemisphere lesion of the same magnitude as $\mathrm{Cblb}$ (Table 6, top). However, the total errors for $\mathrm{Cb} 2$ on the untrained left hand following an even larger right hemisphere lesion $(\mathrm{Cb} 2 \mathrm{c})$ were a third of those for original learning $(\mathrm{Cb} 2 \mathrm{a})$.

The only difference that approached significance between nor- mal Cebus and Galago was the moderate $7-12 \mathrm{~mm}$ comparison, whereas Cebus-area 1 had significantly fewer errors on total errors for the six comparisons as well as on the initial 7-18 mm comparison relative to Galago (Table 6, top; Fig. 11C). Cebusarea 1 and $M a c a c a$ had virtually identical total errors over the six tasks, with no statistically significantly differences found on individual comparisons (Table 6, top; Fig. 12C).

Size ALLS. Compared to their own preoperative performance on size ALLS, Cebus-area 1 performed the same on most of the size comparisons, with little indication that either the lesion or the preoperative experience strongly influenced their capacity. $\mathrm{Cblb}$ performed slightly below the preoperative level when retested on the right hand after the left hemisphere lesion $(4.3 \%)$ while $\mathrm{Cb} 2 \mathrm{~b}$ performed at the preoperative level on its right hand. Percentage correct on the untraincd left hand (following a right hemisphere lesion; $\mathrm{Cb} 2 \mathrm{c}$ ) was $5.3 \%$ higher than its preoperative performance on the right hand ( $\mathrm{Cb} 2 \mathrm{a}$; Table 6 , bottom). It is evident that Cebus-area 1 and Galago performed in a similar range, with Cebus-area 1 doing strikingly better than Galago only on the most difficult comparison $(p=0.058)$. There were no statistically significant differences between Cebus-area 1 and Macaca. Performance on the size ALLS lask was very similar for all four primate species and for Cebus-area 1.

\section{Texture discrimination, Saimiri}

Texture acquisition. Four of the original animals tested on size acquisition and ALLS performance were also trained on texture comparisons. Acquisition profiles are presented in Figure 14 
Figure 12. Bar graphs show the average number of errors made during size acquisition and ALLS performance tasks, comparing Macaca (Carlson, 1984) to Saimiri $(A)$, Cebus (B), and Cebus-area $1(C)$. See Figure 6 for more detail.

\section{SIZE ACQUISITION}

ORDER OF TESTING
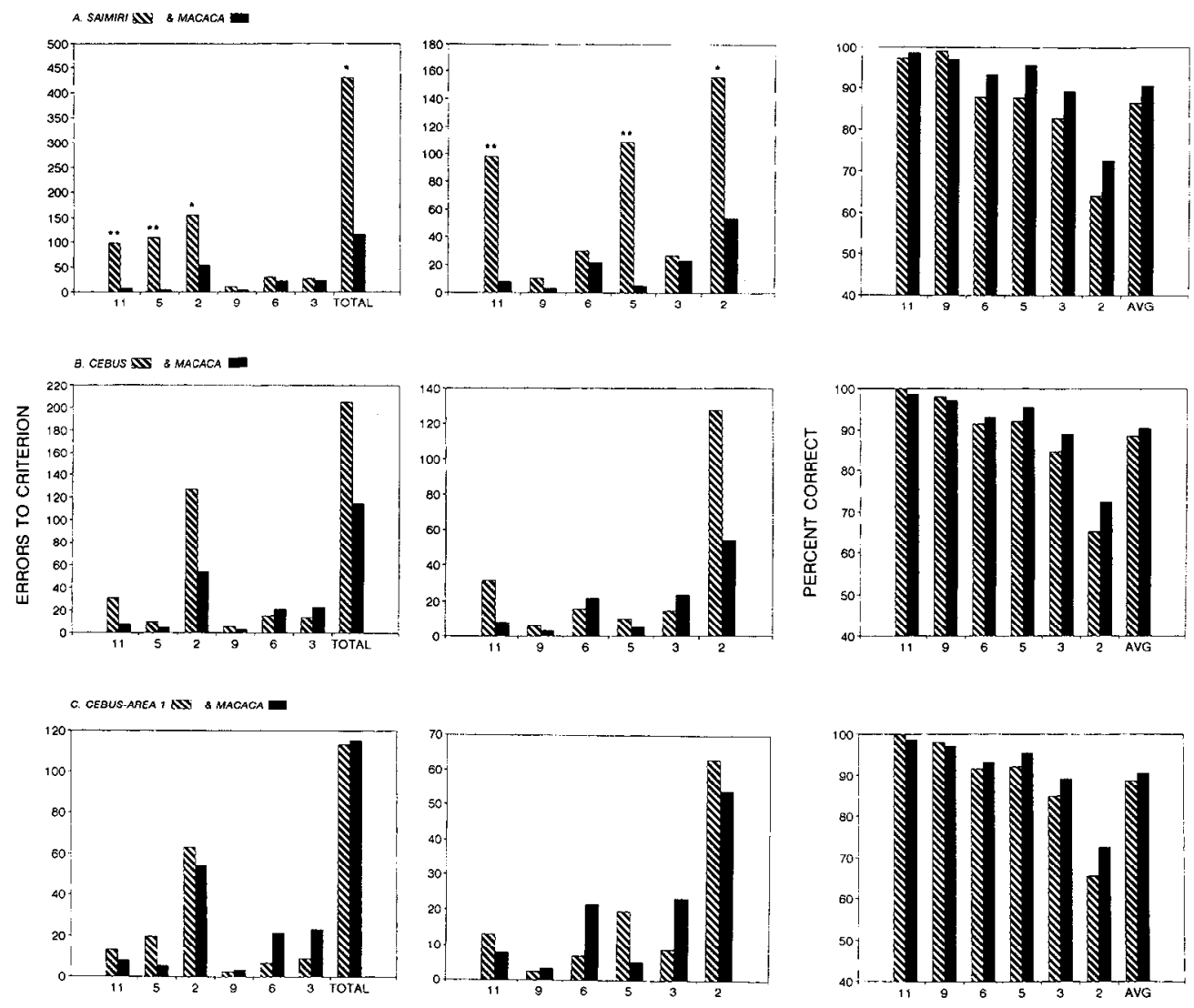

SIZE DIFFERENCES (in mm)
SIZE ALLS

ORDER OF DIFFICULTY
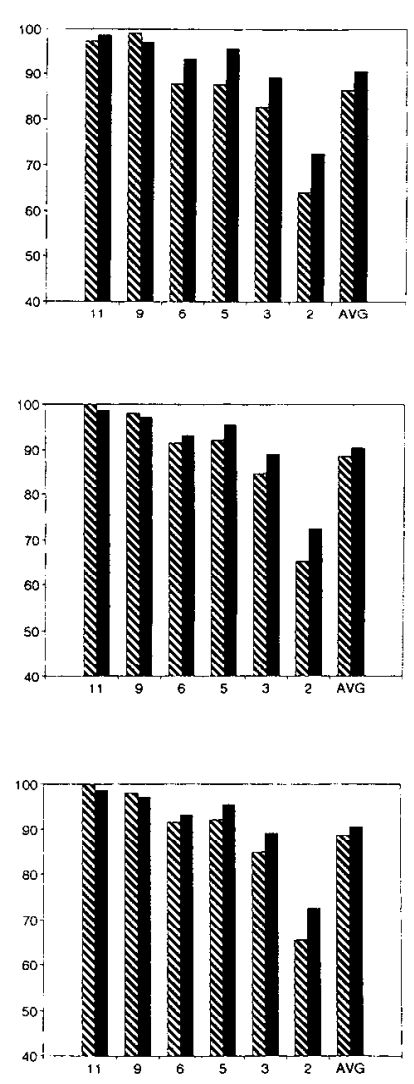

SIZE DIFFERENCES (in $\mathrm{mm}$ ) and errors to criterion are summarized in Table 7 (top). All four Saimiri had difficulty with learning the texture discrimination comparisons and made between $23 \%$ and $63 \%$ more errors than Galago on the first three comparisons presented (Fig. 15A). During training, Ss 4 ran over 40 sessions without mastering the difficult level comparison (320-120 gr/in), but did reach criterion on the intermediate level comparison (320-100 gr/in) after more than 20 sessions. Ss 5 required 40 sessions to reach criterion on that intermediate level, but next showed little evidence of being able to acquire the 320-120 gr/in comparison.

The only statistically significant difference between Saimiri and Galago on individual comparisons was for the $320-80 \mathrm{gr} /$ in comparison. When combining the errors made over all six comparisons, Saimiri madc $43 \%$ more errors than Galago, though this difference did not reach statistical significance. The efficiency with which Saimiri mastered the first three texture comparison was significantly below that of Macaca but with no important differences in their scores on the last three comparisons. (Table 7, top; Fig. 16A). The total errors during texture acquisition by Saimiri were also significantly higher than for Macaca.

Texture ALLS. Although Saimiri performed below Galago on all but the easiest of texture comparisons there were no statistical significant differences between Saimiri and Galago on the texture ALLS task (Table 7, bottom; Fig. 15A). On average Saimiri performed more than $10 \%$ below the level of Macaca, with significant differences found for four of the six comparisons and for the average over all comparisons (Table 7, bottom; Fig. $16 A)$.

\section{Texture discrimination Cebus}

Texture acquisition. The two Cebus were also tested on texture discrimination tasks. The first animal to be tested, Cbla, had difficulty mastering the initial texture comparisons, and because of continued poor performance this animal was given a interruption in testing from week 20 to week 40 (Fig. 14). When testing resumed, $\mathrm{Cbla}$ was retrained on the first two comparisons prior to presenting the third and difficult comparison (320$120 \mathrm{gr} / \mathrm{in})$. After many sessions at below $60 \%$ correct performance on that comparison (and repeated presentations of easier comparisons), an intermediate difficult comparison (320-100 $\mathrm{gr} / \mathrm{in}$ ) was presented and mastered in 12 sessions. After seven more sessions on the $320-120 \mathrm{gr} /$ in comparison with near chance performance, it was decided to proceed with the three remaining comparisons.

The second Cebus to be tested, $\mathrm{Cb} 2 \mathrm{a}$, was more proficient in learning the different texture comparisons. However, during training on the difficult comparison it developed a position habit, and had to be taken back to easier tasks for eight sessions before it reached criterion. $\mathrm{Cb} 2 \mathrm{a}$ never mastered the last comparison (120-80 gr/in) after 10 sessions.

The efficiency with which the two Cebus mastered the texture discrimination comparisons was not significantly different from Galago, except for the $320-80 \mathrm{gr} /$ in comparison (which was also 
Table 5. Size discrimination by Saimiri (in order of difficulty)

\begin{tabular}{|c|c|c|c|c|c|c|c|c|}
\hline & \multicolumn{6}{|c|}{ Size comparisons (difference) } & \multirow[b]{2}{*}{ Total } & \multirow[b]{2}{*}{ Average } \\
\hline & $\begin{array}{l}7-18 \\
\mathrm{~mm} \\
(11 \mathrm{~mm})\end{array}$ & $\begin{array}{l}9-18 \\
\mathrm{~mm} \\
(9 \mathrm{~mm})\end{array}$ & $\begin{array}{l}12-18 \\
\mathrm{~mm} \\
(6 \mathrm{~mm})\end{array}$ & $\begin{array}{l}7-12 \\
\mathrm{~mm} \\
(5 \mathrm{~mm})\end{array}$ & $\begin{array}{l}9-12 \\
\mathrm{~mm} \\
(3 \mathrm{~mm})\end{array}$ & $\begin{array}{l}7-9 \\
\mathrm{~mm} \\
(2 \mathrm{~mm})\end{array}$ & & \\
\hline \multicolumn{9}{|c|}{ Errors to criterion on size acquisition task } \\
\hline Ssla & 40 & 4 & 3 & 91 & 6 & 182 & 326 & - \\
\hline Ss $2 \mathrm{a}$ & 40 & 5 & 31 & 39 & 61 & 63 & 239 & - \\
\hline Ss $3 a$ & 254 & 35 & 97 & 328 & 58 & 205 & 977 & - \\
\hline Ss $4 a$ & 97 & 4 & 13 & 12 & 5 & 306 & 437 & - \\
\hline Ss $5 \mathrm{a}$ & 59 & 4 & 7 & 74 & 5 & 22 & 171 & - \\
\hline AVG Ss & 98.0 & 10.4 & 30.2 & 108.8 & 27.0 & 155.6 & 430.0 & - \\
\hline AVG Gc & 87.4 & 2.0 & 48.3 & 77.1 & 25.9 & 130.4 & 371.1 & - \\
\hline$p$ & NS & NS & NS & NS & NS & NS & NS & - \\
\hline AVG Ss & 98.0 & 10.4 & 30.2 & 108.8 & 27.0 & 155.6 & 430.0 & - \\
\hline AVG Mm & 7.8 & 3.3 & 21.6 & 5.2 & 23.2 & 54.0 & 115.1 & - \\
\hline$p$ & $0.008^{* *}$ & NS & NS & $0.005^{* *}$ & NS & $0.033^{*}$ & $0.020^{*}$ & - \\
\hline \multicolumn{9}{|c|}{ Percentage correct on size ALLS lask } \\
\hline Ssla & 100.0 & 100.0 & 97.4 & 85.9 & 85.9 & 59.5 & - & 88.1 \\
\hline Ss $2 a$ & 100.0 & 100.0 & 98.9 & 96.7 & 87.0 & 68.1 & - & 91.8 \\
\hline Ss $3 a$ & 86.7 & 95.0 & 75.0 & 78.7 & 77.4 & 58.3 & - & 78.5 \\
\hline Ss $4 a$ & 100.0 & 100.0 & 84.0 & 82.7 & 67.3 & 56.4 & - & 81.5 \\
\hline Ss $5 \mathrm{a}$ & 100.0 & 100.0 & 83.3 & 94.0 & 95.9 & 78.0 & - & 91.8 \\
\hline AVG Ss & 97.3 & 99.0 & 87.7 & 87.6 & 82.7 & 64.1 & - & 86.4 \\
\hline AVG Gc & 98.6 & 97.8 & 92.5 & 93.5 & 87.2 & 57.0 & - & 87.7 \\
\hline$p$ & NS & NS & NS & 0.075 & NS & $0.037^{*}$ & - & NS \\
\hline AVG Ss & 97.3 & 99.0 & 87.7 & 87.6 & 82.7 & 64.1 & - & 86.4 \\
\hline AVG $\mathrm{Mm}$ & 98.5 & 97.0 & 93.1 & 95.5 & 89.1 & 72.4 & - & 90.5 \\
\hline$p$ & NS & NS & NS & NS & NS & NS & - & NS \\
\hline
\end{tabular}

true for Saimiri). However, Cebus made more errors than $\mathrm{Ga}$ lago before reaching criterion for all but one of the texture comparisons (Fig. 15B). As a result, Cebus made $36 \%$ more errors overall before mastering all comparisons. There were few statistical differences between Cebus and Macaca in the efficiency of learning the different texture comparisons (Fig. 16B). Although Cebus made more errors on all individual comparisons before reaching criterion than $\mathrm{Macaca}$, only one significant difference was found (320-80 gr/in) and two approached significance (320-40 and $120-40 \mathrm{gr} / \mathrm{in})$. On the total number of errors made across all six comparisons Cebus showed significantly higher errors scores than Macaca (Table 8, top; Fig. 16B).

Texture ALLS. Following acquisition training the two Cebus were tested on the texture ALLS task. With the exceptions of the $320-40$ and $320-80 \mathrm{gr} / \mathrm{in}$ comparisons, performance for both animals was below $80 \%$ correct (Table 8 , bottom). Cebus performed less well than Galago on all six comparisons and on two comparisons ( $120-40$ and $80-40 \mathrm{gr} / \mathrm{in}$ ) Cebus performed significantly below Galago (Table 8, bottom; Fig. 15B). The species difference in average performance on all six tasks approached significance. On average and on all but the two most difficult comparisons, Cebus performed strikingly below $\mathrm{Ma}$ caca ( $p=0.057$; Fig. $16 B$ ), but even for these two difficult comparisons, the percentage correct made by Cebus was at least $12 \%$ lower than for Macaca (Table 8, bottom; Fig. 16B).

\section{Texture discrimination, Cebus-area 1}

Texture acquisition. After the single unilateral lesion in the left hemisphere, $\mathrm{Cbl}$ was retested with its right hand on all six texture comparisons ( $\mathrm{Cbl} b$ ). It mastered all comparisons more quickly and made substantially fewer errors than preoperatively (Cb1a; Table 8, top; Fig. 14). Likewise, $\mathrm{Cb} 2$, after a similar sized lesion of area 1 in its left hemisphere $(\mathrm{Cb} 2 \mathrm{~b})$, mastered all comparisons with its previously trained right hand more efficiently than before the lesion. Following an area 1 lesion in the right hemisphere $(\mathrm{Cb} 2 \mathrm{c}), \mathrm{Cb} 2$ was tested on its left hand. It mastered all six comparisons even more rapidly and with fewer errors although it had never been tested on this hand before (Table 8 , top; Fig. 14).

The remarkable postoperative improvement in efficiency of acquisition of the difficult $320-120 \mathrm{gr} / \mathrm{in}$ led us to present a more difficult comparison, 320-180 gr/in to further explore the apparent improvement in texture discrimination capacity. $\mathrm{Cb} 1$ mastered the $320-180$ gr/in task in 11 sessions with 347 errors, although it never mastered the less discrepant 320-120 gr/in tasks preoperatively after more than 20 sessions. $\mathrm{Cb} 2$ also mastered the 320-180 comparison postoperatively, after 16 sessions and 481 errors on the right hand $(\mathrm{Cb} 2 \mathrm{~b})$ and only 6 sessions and 219 errors on the untrained hand $(\mathrm{Cb} 2 \mathrm{c})$. These errors are not included in the total errors in Table 8 (top) and Figures $15 \mathrm{C}$ and $16 C$.

Postoperatively, Cebus-area 1 made significantly fewer errors than Galago while remastering the three first texture comparisons and on the total over all six comparisons (Fig. 15C). The efficiency with which Cebus-area 1 remastered the texture comparisons was not significantly different from Macaca, except on the initial comparison, which approached significance $(p=0.052$; Table 8, top; Fig. 16C). 

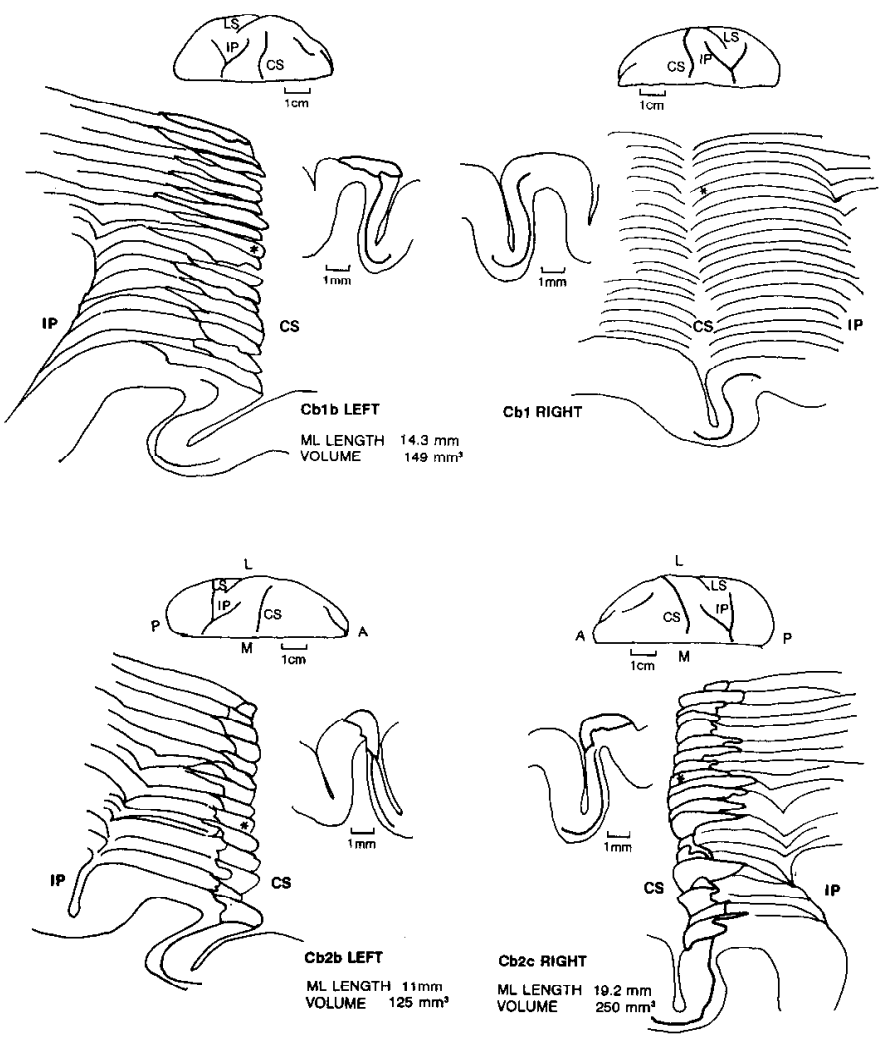

Figure 13. Computer-reconstruction of postcentral gyrus in Cebus, showing configuration of one normal ( $C b 1$ RIGHT) and three area 1lesioned hemispheres (CbIb LEFT, Cb2b LEFT, Cb2c RIGHT) (see Materials and Methods for more details). The brain drawing above each reconstruction shows the relationship of the central sulcus $(C S)$, interparietal sulcus $(I P)$, and lateral sulcus $(I S)$ to the postcentral gyrus. The anterior $(A)$, posterior $(P)$, medial $(M)$, and lateral $(L)$ orientations of the brain drawings, reconstructions, and single cross sections are illustrated on the lower drawings. The relationship of the topographic organization of input from the hand and the cytoarchitectonic areas $(3 \mathrm{~b}$ and 1) to the central sulcus is given in Figure 4. The three-dimensional reconstruction of each hemisphere was based on every 10th section through the lesion, rotated on the $\mathrm{x}, \mathrm{y}, \mathrm{z}$-axes to obtain a dorsomedial view. The profile of each lesion begins with the most medial section through the lesion, with layer VI drawn throughout the postcentral gyrus and precentral gyrus. The dense layer IV, visible in areas $3 \mathrm{a}, 3 \mathrm{~b}$ and 1 , is also shown. A second section, through the middle of the lesion, is identified in the profile by an asterisks, and illustrated next to each series of sections. The mediolateral length and three-dimensional volume of the lesion were calculated from digitalized tracings. The illustration at top right of the normal hemisphere of $C b I R I G H T$, when compared to the three lesioned hemispheres, portrays the reduction of the postcentral gyrus in the anteroposterior plane in the lesioned hemispheres. None of the lesions invaded the white matter, but as shown in the individual cross sections of $\mathrm{Cb} 1 \mathrm{~b}$ and $\mathrm{Cb} 2 \mathrm{c}$, the lesion can be seen as restricted to the upper cortical layers.

Texture ALLS. Compared to their own preoperative performance, Cebus-area 1 performed better on all comparisons and performed above criterion on the average of the six comparisons. Cebus area- 1 performed below $80 \%$ correct on only two comparisons (80-40 and $320-120 \mathrm{gr} / \mathrm{in})$. Cblb continued to perform below $80 \%$ correct on the two difficult comparisons, and $\mathrm{Cb}_{2} 2$ showed greater improvement in performance postoperatively than did $\mathrm{Cbl}$ (Table 8 , bottom). For the average performance across the six comparisons, Cblb showed a $7.2 \%$ improvement, and $\mathrm{Cb} 2 \mathrm{~b}$ an $11 \%$ improvement, on their previously trained right hands. $\mathrm{Cb} 2 \mathrm{c}$ showed a postoperative per- formance level on its untrained left hand that was $12.7 \%$ higher than on its normal right hand (Cb2a). In general, Cebus-area 1 performed better than Galago on all texture comparisons, but only on the difficult 320-120 gr/in comparison did the difference approach significance ( $p=0.058$; Table 8 , bottom; Fig. 15C). Although Macaca typically scored higher than Cebus-area 1 (except for the 320-120 gr/in comparison), there was no significant difference in the performance between them (Fig. 16C). However, the $5 \%$ higher performance by Macaca (averaged across comparisons) approached statistical significancc $(p=0.068)$. Although on average the preoperative performance of Cebus was below that of Saimiri and Galago, postoperative performance levels rose to above Galago yet below Macaca.

\section{Glabrous hand and fool areas and SI rnagnification factors for Saimiri and Cebus}

The average areas for the glabrous hand and foot (and body weights) are given in Table 9. The areas and weights for Saimiri represent the average for two adult males and two adult females. For Cebus, skin surface areas and the body weights for the adult female ( $\mathrm{Cb} 1)$, subadult male ( $\mathrm{Cb} 2)$, and an additional adult male (Cb3) and adult female (Cb4) are presented. For both species, body weight and skin surface areas appear closely correlated. In Saimiri, the skin surface of the glabrous hand was $69 \%$ that of the foot but the combined SI hand areas ( $3 b$ and 1) were only $88 \%$ of the SI foot areas, yet the SI/skin magnification factor for the hand in Saimiri $\left(14.48 \times 10^{-3}\right)$ exceeds that of Galago $\left(4.61 \times 10^{-3}\right)$ and was similar to that of Macaca $\left(15.64 \times 10^{-3}\right)$ (Tables 4, 9). The magnification factor for the SI foot area in Saimiri was greater than for Galago and Macaca.

For Cebus, the skin area of the hand was only $54 \%$ that of the foot whereas the SI hand area was 3.5 times the size of the SI foot area. These remarkable differences in the size of skin surface and SI projection areas (areas $3 b$ and 1) for the hand and foot yielded an extreme difference in magnification factorshand $\left(29.47 \times 10^{-3}\right)$ and foot $\left(4.67 \times 10^{-3}\right)$. The cortical magnification factor for Cebus hand was twice that for the hand in SI of Saimiri and Macaca. The similarities and differences between the expansion of the hand and feet areas in SI and SII in these species suggest that the sensory demands of these two glabrous surfaces may be different for these diverse species.

\section{Discussion}

The choice of behavioral tasks used in this study was based upon our previous experience with a variety of tactile tasks in normal and SI-lesioned adult Macaca. We had expectations as to the behavioral significance of cutaneous input from the glabrous hand to areas $3 \mathrm{~b}$ and 1 , as well as the role of noncutaneous input from the hand to arca 2 . Our choicc of species was based upon the current knowledge available on the structural and functional properties of the somatic sensory system and of taxonomic relations between these different grades (prosimian and anthropoid) and clades (OW and NW lineages) of primates. The results of the behavioral studies will be interpreted in light of information on the structure and function of the tactile system in primates, the use of the hand in natural habitats, and the evolution of the brain in primates of different adaptations and lineages. Finally, we will discuss the structure and function of somatic sensory pathways in different species from a developmental perspective and hypothesize about developmental mechanisms that may underlie the differences in cortical organization that have emerged over the tens of millions of years of evolu- 
Table 6. Size discrimination by Cebus (in order of difficulty)

Size comparisons (difference)

\begin{tabular}{llllllll}
$7-18$ & $9-18$ & $12-18$ & $7-12$ & $9-12$ & $7-9$ & & \\
$\mathrm{~mm}$ & $\mathrm{~mm}$ & $\mathrm{~mm}$ & $\mathrm{~mm}$ & $\mathrm{~mm}$ & $\mathrm{~mm}$ & & \\
$(11 \mathrm{~mm})$ & $(9 \mathrm{~mm})$ & $(6 \mathrm{~mm})$ & $(5 \mathrm{~mm})$ & $(3 \mathrm{~mm})$ & $(2 \mathrm{~mm})$ & Total & Average \\
\hline
\end{tabular}

\begin{tabular}{|c|c|c|c|c|c|c|c|c|}
\hline \multicolumn{9}{|c|}{ Errors to criterion on size acquisition task } \\
\hline Cbla & 40 & 8 & 29 & 8 & 10 & 194 & 289 & - \\
\hline $\mathrm{Cb} 2 \mathrm{a}$ & 23 & 4 & 2 & 12 & 19 & 61 & 121 & - \\
\hline $\mathrm{AVG} \mathrm{Cb}$ & 31.5 & 6.0 & 15.5 & 10.0 & 14.5 & 127.5 & 205.0 & - \\
\hline AVG Gc & 87.4 & 2.0 & 48.3 & 77.1 & 25.9 & 130.4 & 371.1 & - \\
\hline$p$ & NS & NS & NS & 0.056 & NS & NS & NS & - \\
\hline $\mathrm{AVG} \mathrm{Cb}$ & 31.5 & 6.0 & 15.5 & 10.0 & 14.5 & 127.5 & 205.0 & - \\
\hline AVG $\mathrm{Mm}$ & 7.8 & 3.3 & 21.6 & 5.2 & 23.2 & 54.0 & 115.1 & - \\
\hline$p$ & NS & NS & NS & NS & NS & NS & NS & - \\
\hline $\mathrm{Cb} 1 \mathrm{~b}$ & 32 & 0 & 6 & 45 & 11 & 74 & 168 & - \\
\hline $\mathrm{Cb} 2 \mathrm{~b}$ & 5 & 7 & 4 & 10 & 6 & 101 & 133 & - \\
\hline $\mathrm{Cb} 2 \mathrm{c}$ & 2 & 0 & 10 & 4 & 9 & 14 & 39 & - \\
\hline$A \vee G C b-1$ & 13.0 & 2.3 & 6.7 & 19.7 & 8.7 & 63.0 & 113.3 & - \\
\hline $\mathrm{AVG} G \mathrm{c}$ & 87.4 & 2.0 & 48.3 & 77.1 & 25.9 & 130.4 & 371.1 & - \\
\hline$p$ & $0.017^{*}$ & NS & NS & NS & NS & NS & $0.008^{* *}$ & - \\
\hline AVG Cb-1 & 13.0 & 2.3 & 6.7 & 19.7 & 8.7 & 63.0 & 113.3 & - \\
\hline AVG Mm & 7.8 & 3.3 & 21.6 & 5.2 & 23.2 & 54.0 & 115.1 & - \\
\hline$p$ & NS & NS & NS & NS & NS & NS & NS & - \\
\hline \multicolumn{9}{|c|}{ Percentage correct on size ALLS task } \\
\hline Cbla & 100.0 & 97.8 & 91.1 & 92.3 & 84.6 & 65.2 & - & 88.5 \\
\hline $\mathrm{Cb} 2 \mathrm{a}$ & 100.0 & 97.9 & 92.0 & 91.9 & 84.9 & 65.6 & - & 88.8 \\
\hline $\mathrm{AVG} \mathbf{C b}$ & 100.0 & 97.9 & 91.6 & 92.1 & 84.7 & 65.4 & - & 88.7 \\
\hline AVG Gc & 98.6 & 97.8 & 92.5 & 93.5 & 87.2 & 57.0 & - & 87.7 \\
\hline$p$ & NS & NS & NS & NS & NS & NS & - & NS \\
\hline $\mathrm{AVG} \mathrm{Cb}$ & 100.0 & 97.9 & 91.6 & 92.1 & 84.7 & 65.4 & - & 88.7 \\
\hline AVG $\mathrm{Mm}$ & 98.5 & 97.0 & 93.1 & 95.5 & 89.1 & 72.4 & - & 90.5 \\
\hline$p$ & NS & NS & NS & NS & NS & NS & - & NS \\
\hline $\mathrm{Cblb}$ & 97.8 & 96.6 & 83.2 & 92.1 & 77.5 & 58.0 & - & 84.2 \\
\hline $\mathrm{Cb} 2 \mathrm{~b}$ & 100.0 & 100.0 & 90.2 & 97.7 & 90.4 & 61.6 & - & 89.9 \\
\hline $\mathrm{Cb} 2 \mathrm{c}$ & 100.0 & 100.0 & 97.9 & 94.8 & 92.6 & 79.2 & - & 94.1 \\
\hline AVG Cb-1 & 99.3 & 98.9 & 90.4 & 94.9 & 86.8 & 66.3 & - & 89.4 \\
\hline AVG Gc & 98.6 & 97.8 & 92.5 & 93.5 & 87.2 & 57.0 & - & 87.7 \\
\hline$p$ & NS & NS & NS & NS & NS & 0.058 & - & NS \\
\hline AVG Cb-1 & 99.3 & 98.9 & 90.4 & 94.9 & 86.8 & 66.3 & - & 89.4 \\
\hline AVG Mm & 98.5 & 97.0 & 93.1 & 95.5 & 89.1 & 72.4 & - & 90.5 \\
\hline$p$ & NS & NS & NS & NS & NS & NS & - & NS \\
\hline
\end{tabular}

tionary history that separate these species. Furthermore, we speculate about how different developmental events may account for the pattern of thalamocortical connections and tactile behavior capacity typical of individual species. Without such a developmental perspective one cannot expect to understand the mechanisms by which species-specific patterns (or individual variation within species) are achieved.

The general and specific contributions of somatic sensory cortex to tactile discrimination capacity in adult Macaca

Our previous behavioral studies in adult Macaca demonstrated the selective contribution of area 2 to size and shape discrimination abilities and of area 1 to texture discrimination skill, whereas area $3 b$ was found to be necessary for all tactile discrimination capacity (Randolph and Semmes, 1974; Carlson, 1981). The selective and independent deficits associated with damage to these two SI areas from either area 1 or 2 suggest a specificity of function referred to as double dissociation of function in the literature on localization of cortical function (Teuber, 1955; Carlson, 1981). Similar to the general contribution of $3 \mathrm{~b}$ revealed by the selective lesion technique, ablations of area SII in the lateral sulcus (but not area 5 in the posterior parietal region) produce severe and lasting deficits on a variety of tactile discrimination tasks (Ridley and Ettlinger, 1976, 1978; Murray and Mishkin, 1984). Although $3 \mathrm{~b}$ and SII lesions do not produce the double dissociation of function characterizing areas 1 and 2 lesions, these two areas are necessary for normal levels of tactile function in adult Macaca. It is the specific contribution of input from the glabrous hand to area 1 that is of special interest in the present study. By including both size and texture discrimination, it is possible to discuss the modality-specific aspects (cutaneous vs noncutaneous) of the two classes of tasks (texture vs size) from the general sensorimotor and cognitive aspects of the tasks. 


\section{TEXTURE ACQUISITION}

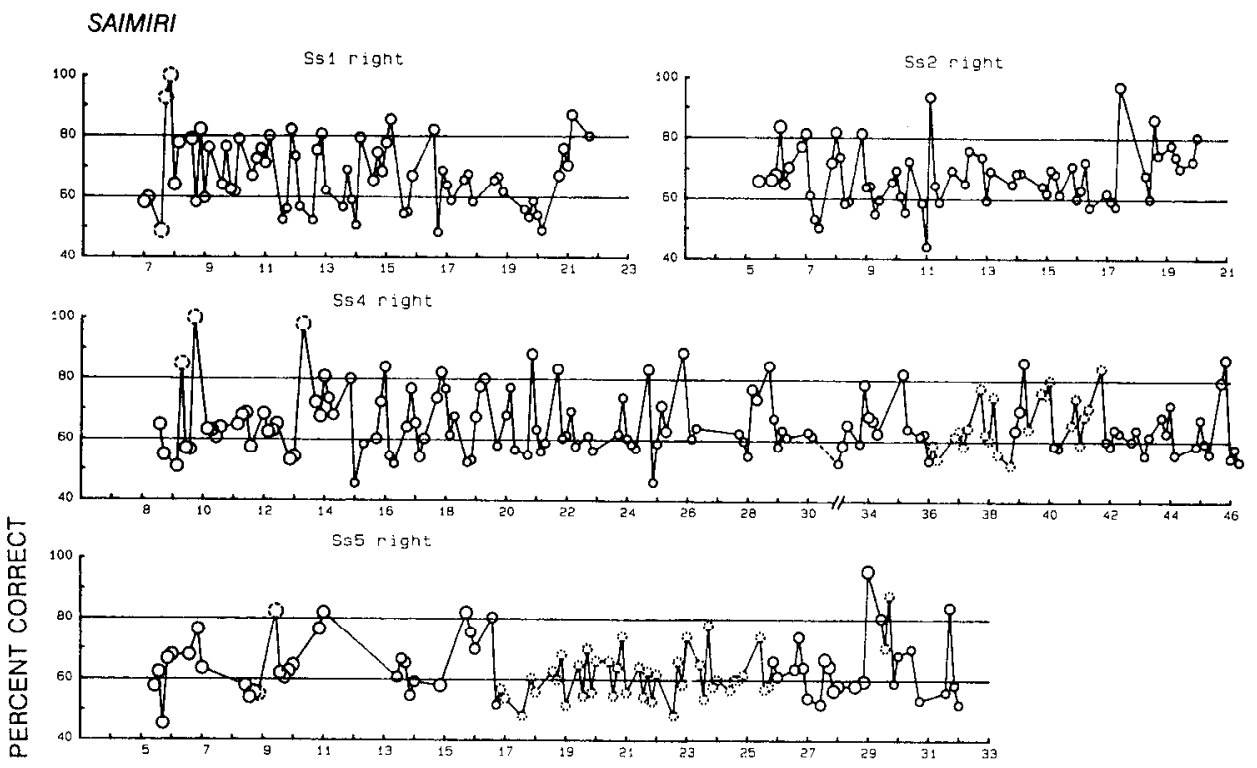

CEBUS
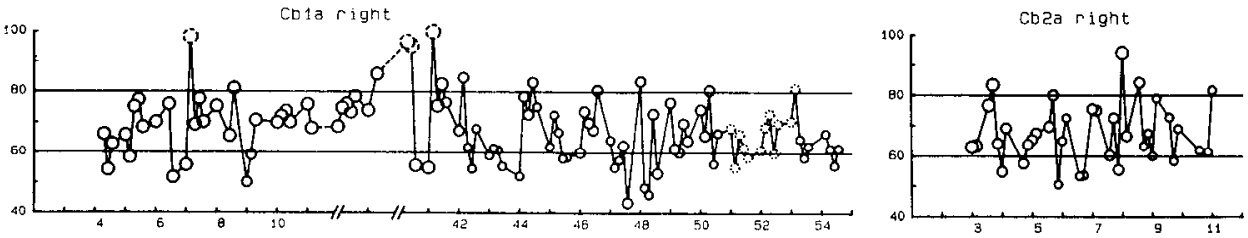
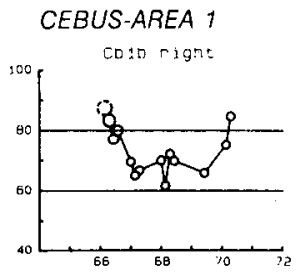

Figure 14. Individual acquisition profiles for texture tasks by normal Saimiri (Ss I-Ss5), normal Cebus (Cbla, $\mathrm{Cb} 2 a)$, and Cebus-area 1 (Cblb, Cb2b/ $c)$ are illustrated. See Figure 5 for additional details.
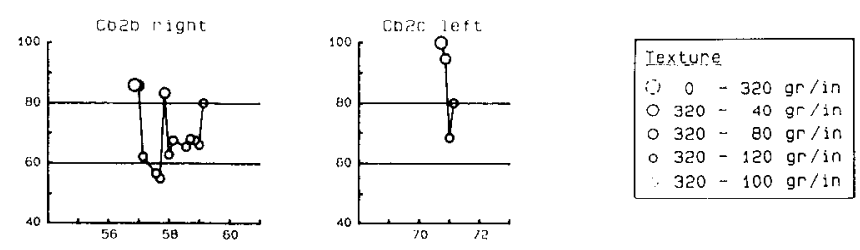

WEEKS OF TESTING
It was not unexpected that Galago (a prosimian primate that diverged from the common evolutionary lineage tens of millions of years before anthropoid primates) would make more errors than Macaca and require more sessions prior to criterion during the early acquisition sessions due to the nonsensory demands of the tasks alone. General sensorimotor demands of these tasks includc such bchaviors as reaching, pulling, touching, and comparing both handles in a pair from trial to trial. Cognitive demands include attending to either the size or texture cues and transferring response strategies from one level of difficulty to another and abandoning the previous strategy when shifting from size to texture tasks.

Accounting for some general, nonsensory differences between Macaca, Saimiri and Cebus is more difficult, as they are all classified as anthropoids and as sharing the same grade (or general complexity) of structural organization. Cebus are considered to be the most "clever" and inquisitive of the NW primates (e.g., Klüver, 1937; Chevalier-Skolnikoff, 1989). Their manipulative skills and sensorimotor "intelligence" have been examined extensively and are thought to rival that of Macaca
(Torigoe, 1985; Gibson, 1986; Chevalier-Skolnikoff, 1989) and to exceed that of Saimiri (Costello and Fragaszy, 1988). Our predictions were therefore that the efficiency of learning on all tactile tasks by Cebus would be more like Macaca than Galago. Because of the more limited hand use in Saimiri (and some parallels between the way Saimiri and Galago use their hands when grasping objects) it was possible that Saimiri would be more like Galago than Macaca. Differences on size and texture tasks related to nonsensory capacity like "intelligence" were expected to be reflected by greater difficulty with initial comparisons of the size and texture tasks (order of testing) rather than a function of physical differences (order of difficulty).

\section{Size discrimination capacity in Macaca and Galago}

Earlier studies of normal adult Macaca showed that they can reliably discriminate a $1-1.5 \mathrm{~mm}$ difference from a $12.7 \mathrm{~mm}$ standard handle (Semmes and Mishkin, 1965; Randolph and Semmes, 1974). In a later study of infant and juvenile Macaca (Carlson, 1984), the standard size handle was reduced to $7 \mathrm{~mm}$, a size more appropriate for younger macaques and for the spe- 
TEXTURE ACQUISITION
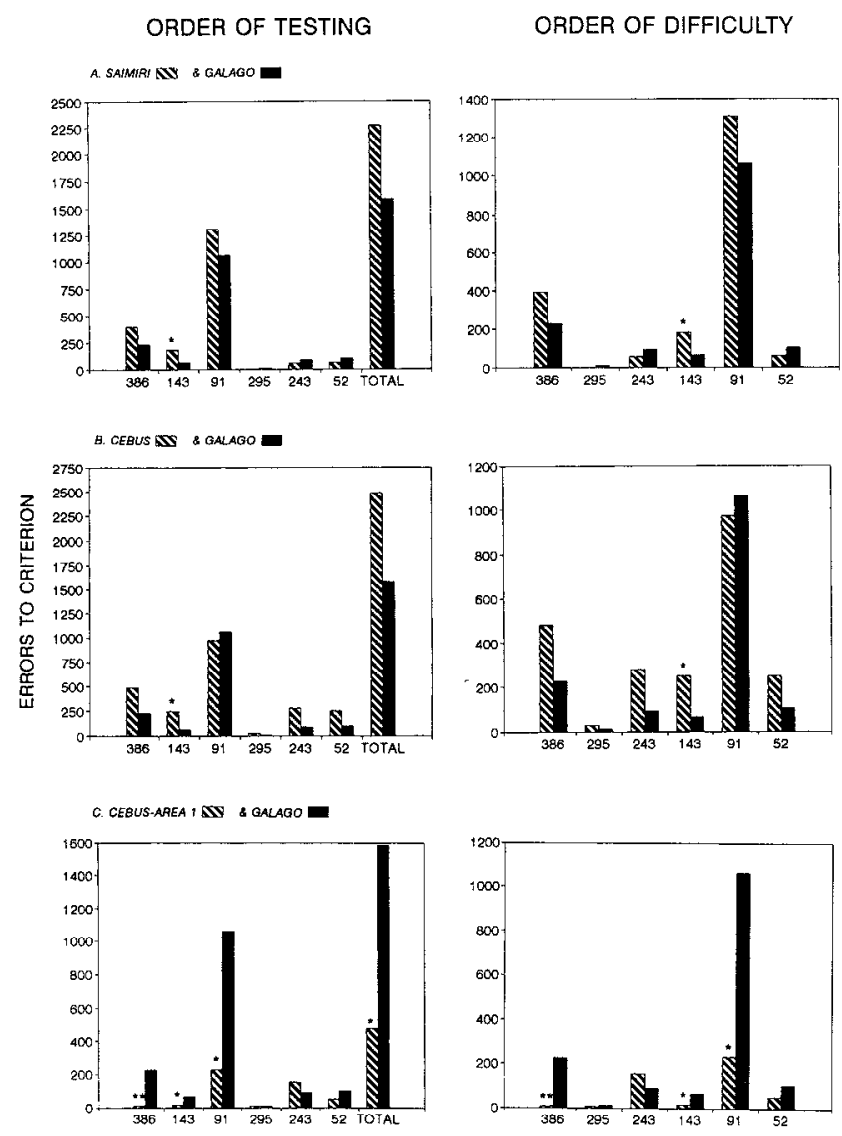

TEXTURE DIFFERENCES (in $\mu \mathrm{m}$ )

\section{TEXTURE ALLS}

ORDER OF DIFFICULTY
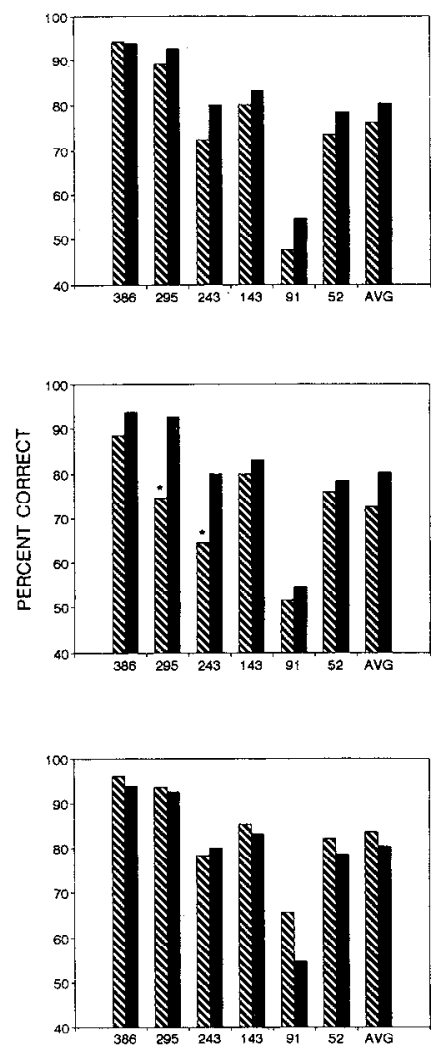

TEXTURE DIFFERENCES (in $\mu \mathrm{m})$
Figure 15. Bar graphs show the average number of errors made during texture acquisition and ALLS performance, comparing Galago to Saimiri $(A)$, Cebus $(B)$, and Cebus-area $1(C)$. See Figure 6 for more detail. cies in the present study. Ablation studies have shown that removal of area 2 in SI of Macaca results in a deficit in size discrimination ability, consistent with the predominance of noncutaneous input to this area from receptors associated with joint and muscles (Powell and Mountcastle, 1959; Schwarz et al., 1973). Similarly, in physiological studies of awake Galago, we found activity in areas 2-5 and $3 a$ to be activated by noncutaneous input (Carlson and Welt, 1980). The findings of the present studies that Galago could master all levels of difficulty of size acquisition tasks and was not significantly different from Macaca on five of the six size threshold comparisons are compatible with these physiological findings. However, the significant difference between Macaca and Galago on the difficult 7$9 \mathrm{~mm}$ ( $2 \mathrm{~mm}$ difference) comparison indicates that, although both species have the same sensory capacity over a wide range of size comparisons, Galago cannot maintain the same level of performance as Macaca on this difficult comparison during the more complex ALLS task.

The ALLS task is more demanding than the acquisition task since the animals are required to make relative judgements across trials, as a handle that was correct on one trial may be incorrect on next trial if paired with a smaller handle. These two species differed significantly on the first two comparisons in order of testing rather than on the most difficult comparisons. Galago exhibited more difficulty with the initial size acquisition tasks (ranked by order of testing) than with the three most difficult tasks (ranked by the millimeter differences between handles).
By contrast, the pattern of errors for Macaca was related more to the order of difficulty. It was on the third and most difficult comparison ( $7-9 \mathrm{~mm}$ ) that both species showed the highest error scores during acquisition and the lowest percentage correct during the ALLS task. It was expected that the error scores of Galago and Macaca would be more similar on later comparisons and on the size ALLS task, since the differences in general learning capacity became less relevant and sensory demands of the tasks more relevant.

A possible explanation for this finding is that nonsensory abilities, such as the capacity of Galago to concentrate consistently on the demands of the task, influence the animal's ability to perform consistently near its sensory threshold for size. Alternatively, it may be that receptors associated with joints and muscles do not project with the same degree of accuracy information about finger position or movement. Furthermore, in Galago cortical areas 3a, 2, and 5 (or cuneate or thalamic nuclei) may receive and integrate information from the hand less efficiently or reliably than in Macaca, yet Galago performed remarkably similar to Macaca over a range of size comparisons following initial acquisition, and it was only on the discrimination of the smallest difference that species differences persisted in the ALLS task.

A third possibility (one that we favor) is that the vast difference in hand and finger control in these species limits the capacity of Galago to perform the smallest discriminations reliably. Galago hand control is characterized as whole hand 
Table 7. Texture discrimination by Saimiri (in order of difficulty)

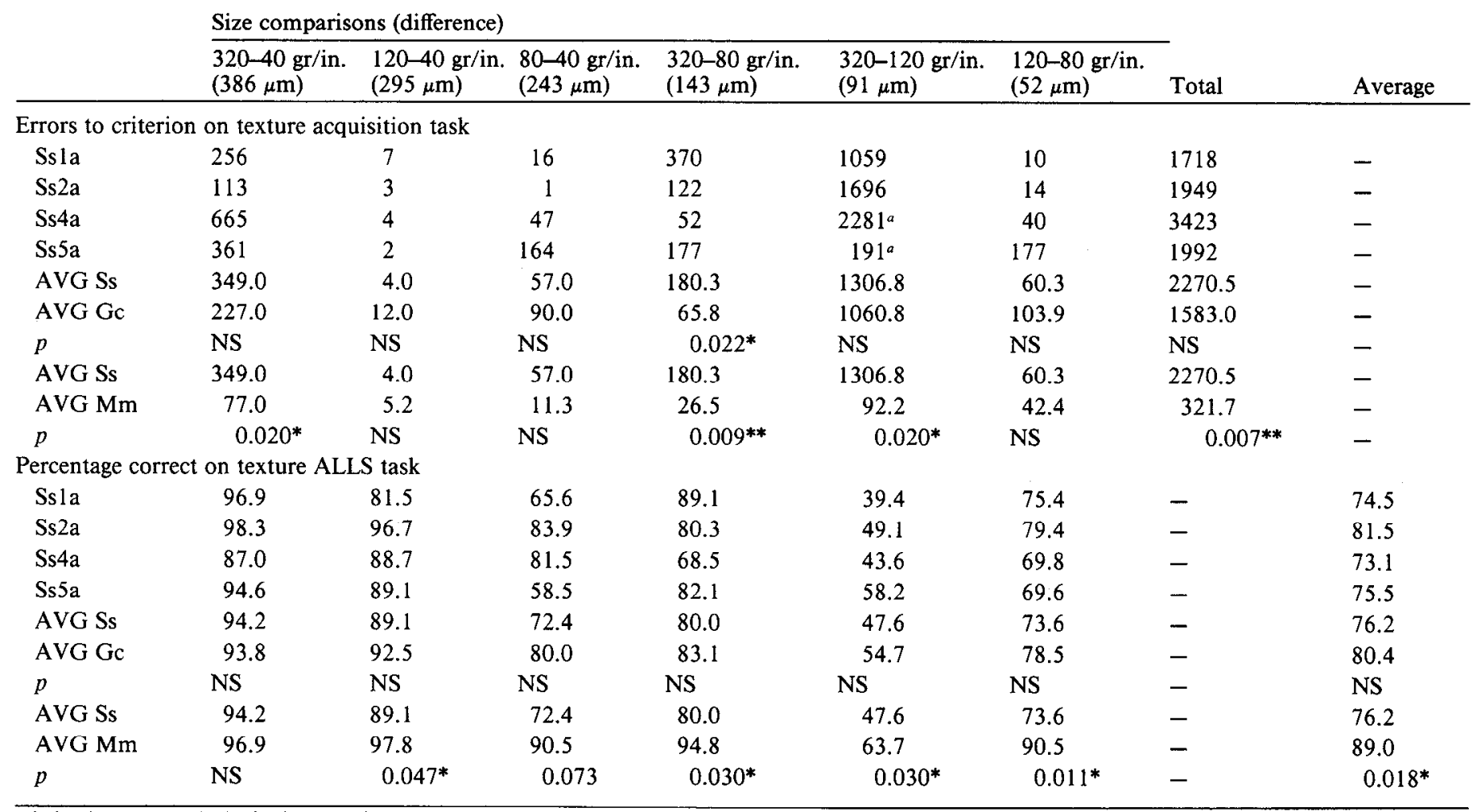

a Animals never reached criterion on this task.

${ }^{*}, p \leqq 0.05 ;{ }^{* *}, p \leqq 0.01 ;{ }^{* * *}, p \leqq 0.001$.

TEXTURE ACQUISITION

ORDER OF TESTING
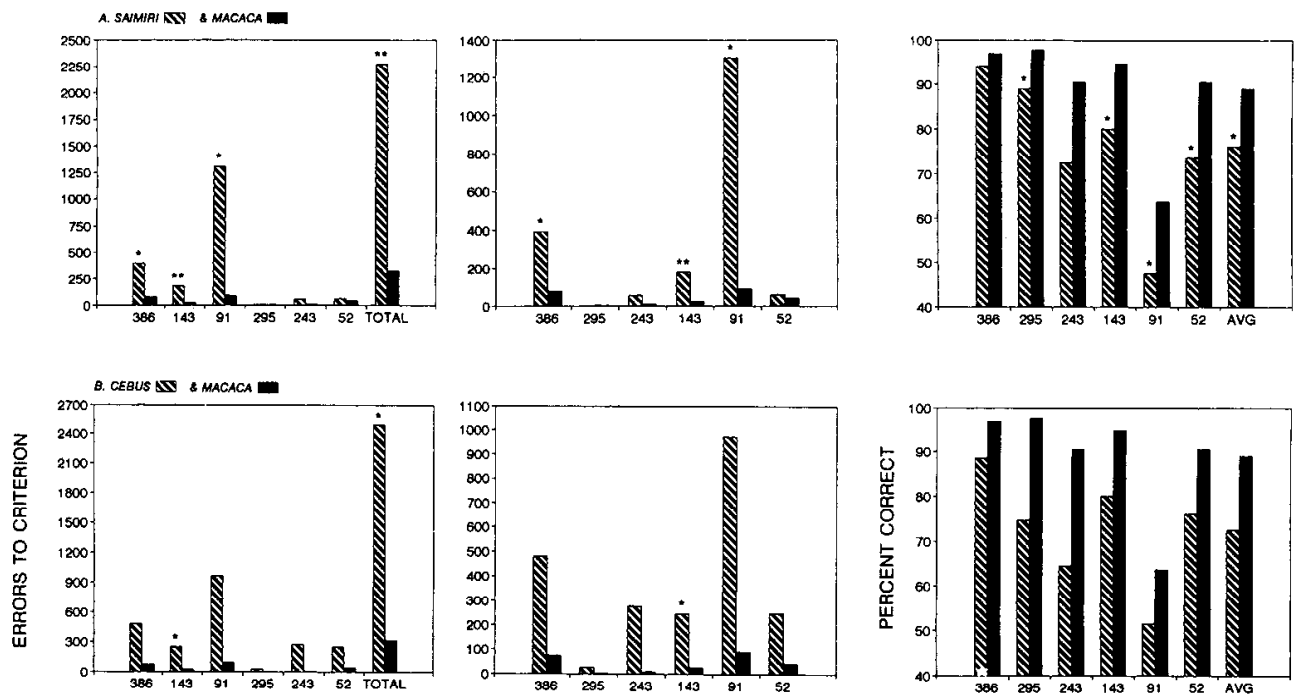

Figure 16. Bar graphs show the average number of errors made during texture acquisition and ALLS performance tasks, comparing Macaca to Saimiri $(A)$, Cebus $(B)$, and Cebus-area $1(C)$. See Figure 6 for more detail.
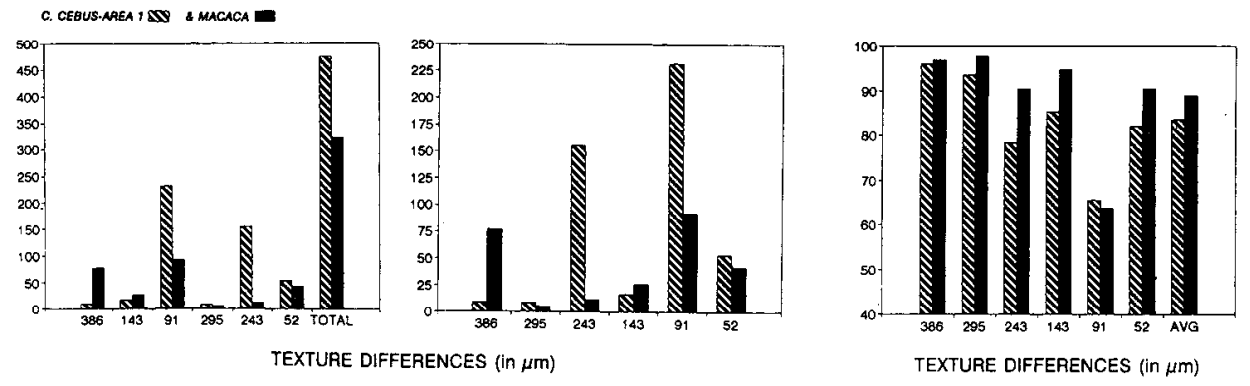
Table 8. Texture discrimination by Cebus (in order of difficulty)

\begin{tabular}{|c|c|c|c|c|c|c|c|c|}
\hline & \multicolumn{6}{|c|}{ Size comparisons (difference) } & \multirow[b]{2}{*}{ Total } & \multirow[b]{2}{*}{ Average } \\
\hline & $\begin{array}{l}320-40 \mathrm{gr} / \mathrm{in} . \\
(386 \mu \mathrm{m})\end{array}$ & $\begin{array}{l}120-40 \mathrm{gr} / \mathrm{in} . \\
(295 \mu \mathrm{m})\end{array}$ & $\begin{array}{l}80-40 \mathrm{gr} / \mathrm{in} . \\
(243 \mu \mathrm{m})\end{array}$ & $\begin{array}{l}320-80 \mathrm{gr} / \mathrm{in} . \\
(143 \mu \mathrm{m})\end{array}$ & $\begin{array}{l}320-120 \mathrm{gr} / \mathrm{in} . \\
(91 \mu \mathrm{m})\end{array}$ & $\begin{array}{l}120-80 \mathrm{gr} / \mathrm{in} . \\
(52 \mu \mathrm{m})\end{array}$ & & \\
\hline \multicolumn{9}{|c|}{ Errors to criterion on texture acquisition task } \\
\hline Cbla & 793 & 37 & 546 & 176 & $1231^{a}$ & 47 & 3297 & - \\
\hline $\mathrm{Cb} 2 \mathrm{a}$ & 171 & 18 & 11 & 321 & 711 & $453^{a}$ & 1685 & - \\
\hline $\mathrm{AVG} \mathrm{Cb}$ & 482.0 & 27.5 & 278.5 & 248.5 & 971.0 & 250.0 & 2491.0 & - \\
\hline AVG Gc & 227.0 & 12.0 & 90.0 & 65.8 & 1060.8 & 103.9 & 1583.0 & - \\
\hline$p$ & NS & NS & NS & $0.022^{*}$ & NS & NS & NS & - \\
\hline $\mathrm{AVG} \mathrm{Cb}$ & 482.0 & 27.5 & 278.5 & 248.5 & 971.0 & 250.0 & 2491.0 & - \\
\hline AVG Mm & 77.0 & 5.2 & 11.3 & 26.5 & 92.2 & 42.4 & 321.7 & - \\
\hline$p$ & 0.068 & 0.068 & NS & $0.041^{*}$ & NS & NS & $0.045^{*}$ & - \\
\hline $\mathrm{Cbib}$ & 17 & 16 & 446 & 35 & 281 & 145 & 940 & - \\
\hline $\mathrm{Cb} 2 \mathrm{~b}$ & 10 & 7 & 11 & 12 & 363 & 6 & 409 & - \\
\hline $\mathrm{Cb} 2 \mathrm{c}$ & 0 & 3 & - & 4 & 51 & 8 & 75 & - \\
\hline AVG Cb-1 & 9.0 & 8.7 & 155.0 & 17.0 & 231.7 & 53.0 & 474.7 & - \\
\hline AVG Gc & 227.0 & 12.0 & 90.0 & 65.8 & 1060.8 & 103.9 & 1583.0 & - \\
\hline$p$ & $0.006^{* *}$ & NS & NS & $0.042^{*}$ & $0.042^{*}$ & NS & $0.012^{*}$ & - \\
\hline AVG Cb-1 & 9.0 & 8.7 & 155.0 & 17.0 & 231.7 & 53.0 & 474.7 & - \\
\hline AVG Mm & 77.0 & 5.2 & 11.3 & 26.5 & 92.2 & 42.4 & 321.7 & - \\
\hline$p$ & 0.052 & NS & NS & NS & NS & NS & NS & - \\
\hline \multicolumn{9}{|c|}{ Percentage correct on texture ALLS task } \\
\hline Cbla & 91.0 & 69.0 & 63.0 & 80.0 & 56.0 & 64.0 & - & 70.5 \\
\hline $\mathrm{Cb} 2 \mathrm{a}$ & 86.0 & 80.2 & 66.0 & 80.0 & 47.0 & 88.0 & - & 74.5 \\
\hline $\mathrm{AVG} \mathrm{Cb}$ & 88.5 & 74.6 & 64.5 & 80.0 & 51.5 & 76.0 & - & 72.5 \\
\hline AVG Gc & 93.8 & 92.5 & 80.0 & 83.1 & 54.7 & 78.5 & - & 80.4 \\
\hline$p$ & NS & $0.028^{*}$ & $0.028^{*}$ & NS & NS & NS & - & 0.056 \\
\hline $\mathrm{AVG} \mathrm{Cb}$ & 88.5 & 74.6 & 64.5 & 80.0 & 51.5 & 76.0 & - & 72.5 \\
\hline AVG Mm & 96.9 & 97.8 & 90.5 & 94.8 & 63.7 & 90.5 & - & 89.0 \\
\hline$p$ & 0.057 & 0.057 & 0.057 & 0.057 & NS & NS & - & 0.057 \\
\hline Cblb & 88.0 & 86.8 & 63.2 & 84.2 & 72.7 & 71.4 & - & 77.7 \\
\hline $\mathrm{Cb} 2 \mathrm{~b}$ & 100.0 & 96.3 & 90.0 & 80.8 & 57.0 & 88.9 & - & 85.5 \\
\hline $\mathrm{Cb} 2 \mathrm{c}$ & 100.0 & 97.8 & 81.7 & 90.9 & 67.0 & 86.0 & - & 87.2 \\
\hline AVG Cb-1 & 96.0 & 93.6 & 78.3 & 85.3 & 65.6 & 82.1 & - & 83.5 \\
\hline AVG Gc & 93.8 & 92.5 & 80.0 & 83.1 & 54.7 & 78.5 & - & 80.4 \\
\hline$p$ & NS & NS & NS & NS & 0.058 & NS & - & NS \\
\hline AVG $\mathrm{Cb}-1$ & 96.0 & 93.6 & 78.3 & 85.3 & 65.6 & 82.1 & - & 83.5 \\
\hline AVG Mm & 96.9 & 97.8 & 90.5 & 94.8 & 63.7 & 90.5 & - & 89.0 \\
\hline$p$ & NS & NS & NS & NS & NS & NS & - & 0.068 \\
\hline
\end{tabular}

a Animals did not reach criterion on this task.

${ }^{*}, p \leqq 0.05 ;^{* *}, p \leqq 0.01 ;^{* *}, p \leqq 0.001$.

response, consisting of a rapid, stereotyped five-finger grasp movement (Bishop, 1964). This type of hand control does not appear to have the same potential for information about finger position and movement as the slow, dexterous, and more independent finger movement typical of Macaca. Although there has been much speculation about the role of manual dexterity in tactile capacity, studies of adult and infant Macaca failed to demonstrate sensory deficits on size or texture discrimination tasks following lesions of the hand area in primary motor cortex (Semmes and Porter, 1972; Carlson, 1984), yet hand movements of Galago do not resemble those of an area 4-lesioned Macaca but rather reflect the highly stereotypical grasp response of prosimians.

In conclusion, more limited cognitive abilities, less accurate cortical processing of finger movement and position, and less proficient manual dexterity may all contribute to the inferior performance by Galago on the most difficult size comparison in the ALLS tasks. The comparable size discrimination capacity of Macaca (with an expanded SI and SII, and a more complex SI topography) compared to that of Galago (with a smaller SI and SII, and less complex SI) suggests that the noncutaneous input to areas 2 and $3 \mathrm{a}$ in SI, cutaneous input to $3 \mathrm{~b}$ and SII was sufficient to mediate the level of capacity demanded by the range of size comparisons presented in this study.

\section{Size discrimination capacity in Saimiri and Ccbus}

The same characteristic noncutaneous input to area 2 (and 3a) in Galago and Macaca has been described in Cebus and Saimiri (Sur et al., 1982; Felleman et al., 1983). Thus, there was no reason to assume that NW anthropoids were deficient in the cortical projection of noncutaneous input shown to be required for size discrimination capacity in Macaca (Randolph and Semmes, 1974; Carlson, 1981). Because of this common SI input and the shared anthropoid grade of organization, we expected 
Table 9. Cortical magnification factors for SI

\begin{tabular}{|c|c|c|c|c|c|c|c|}
\hline \multicolumn{5}{|c|}{ Saimiri sciureus } & \multirow{2}{*}{$\begin{array}{l}\text { Skin } \\
\operatorname{area}^{a} \\
\left(\mathrm{~mm}^{2}\right)\end{array}$} & \multirow{2}{*}{$\begin{array}{l}\text { SI } \\
\operatorname{area}^{b} \\
\left(\mathrm{~mm}^{2}\right)\end{array}$} & \multirow{2}{*}{$\begin{array}{l}\text { Mag } \\
\left(10^{-3}\right)\end{array}$} \\
\hline Ss & Ss1 & Ss 3 & Ss 4 & Ss5 & & & \\
\hline$G$ hand & 936.3 & 1095.5 & 1255.5 & 855.2 & 1035.6 & 15 & (14.48) \\
\hline$G$ foot & 1349.63 & 1552.6 & 1786 & 1274.7 & 1490.73 & 17 & (11.40) \\
\hline Weight & 695 & 1000 & 1050 & 595 & 835 & & \\
\hline \multicolumn{5}{|c|}{ Cebus apella } & \multirow{2}{*}{$\begin{array}{l}\text { Skin } \\
\text { area } \\
\left(\mathrm{mm}^{2}\right)\end{array}$} & \multirow{2}{*}{$\begin{array}{l}\text { SI } \\
\text { area }^{c} \\
\left(\mathrm{~mm}^{2}\right) \\
\end{array}$} & \multirow{2}{*}{$\begin{array}{l}\text { Mag } \\
\left(10^{-3}\right)\end{array}$} \\
\hline $\mathrm{Cb}$ & $\mathrm{Cbl}$ & $\mathrm{Cb} 2$ & $\mathrm{Cb} 3$ & $\mathrm{Cb} 4$ & & & \\
\hline$G$ hand & 1830.1 & 1082.5 & 3188.3 & 1908.8 & 2002.4 & 59 & $(29.47)$ \\
\hline$G$ foot & - & 3352.3 & 4518.3 & 3197.4 & 3689.3 & 17 & $(4.67)$ \\
\hline Weight & 2335 & 1765 & 4900 & 1940 & 2735 & & \\
\hline
\end{tabular}

${ }^{a}$ Average of Ss1, Ss3, Ss4, Ss5.

"From Sur et al. (1982).

' From Felleman et al. (1983).

Saimiri and Cebus to perform as well as Macaca and Galago on these tasks.

The results from the size discrimination tasks showed that Saimiri and Cebus differed in learning efficiency from each other and from Macaca on the first three size comparisons. Saimiri amassed slightly more errors overall than Galago and significantly more errors than Macaca on size acquisition. Compared to Galago, Cebus made half the number of errors, while compared to Macaca they made twice as many errors. These results suggest that Saimiri learned at a rate more similar to Galago, whereas the learning rate for Cebus was between that of Galago and Macaca. On the size ALLS, Saimiri and Cebus (both normal and area 1-lesioned) were significantly better than Galago on the difficult size comparisons but insignificantly below the level of Macaca on all comparisons. These findings further support the interpretation that area 1 does not contribute to size discrimination capacity, consistent with studies of normal and area 1-lesioned Macaca (Randolph and Semmes, 1974; Carlson, 1981). Results from the size tasks also show that all four species have comparable nonsensory capacities necessary to acquire a series of tactile discrimination tasks and to transfer the skill from acquisition training to performance on the more complex ALLS task.

\section{Texture discrimination capacity in Galago and Macaca}

Previous studies of Macaca report thresholds, using the same texture comparison in the present study, of between 180 and $150 \mathrm{gr} /$ in when compared to a $320 \mathrm{gr} /$ in standard (Semmes and Mishkin, 1965). When these same comparisons were presented to area 1-lesioned adult Macaca tested postoperatively only, thresholds between 120 and $100 \mathrm{gr} / \mathrm{in}$ were obtained. Adult Macaca with preoperative training on these same texture tasks failed postoperatively to reacquire the $320-180 \mathrm{gr} / \mathrm{in}$ comparison (Carlson, 1981).

By the time the present subjects were tested on texture tasks they had considerable exposure to the nonsensory aspects of the testing situation, allowing for sensory capacity to play a clearer role in acquisition and performance than during the size task. During the texture acquisition task, both Galago and Macaca showed the most errors on the initial (but easy) comparison and the third (difficult, but not the most physically discrepant) texture comparison. This comparison (constituting a $91 \mu \mathrm{m}$ dif- ference) was based on two smooth surfaces, as opposed to the less discrepant $52 \mu \mathrm{m}$ difference comparison which was between two rougher surfaces (120-80 gr/in, comprising a smaller relative difference but between two larger grain sizes). The $91 \mu \mathrm{m}$ difference comparison was typically the most difficult for all species and individuals tested on this texture series. The greater difficulty of the $91 \mu \mathrm{m}$ comparison $(320-120 \mathrm{gr} / \mathrm{in})$ was seen both in the errors to criterion in acquisition and in percentage correct on the texture ALLS task (where there is no order effect) suggesting a true sensory-based difference.

On the initial texture comparison both species were less efficient than would be expected by the grain size or grain spacing dimensions of the task. When confronted with the first texture comparisons, many animals (regardless of species) show either random response strategies or fixed position habits. After months of training to detect size differences, subjects were forced to explore other dimensions of the handles to determine that texture cues were the significant feature to discriminate when confronted with handles of the same diameter.

After mastering the first texture comparison, Galago was still significantly less efficient than Macaca on the second, moderatelevel comparison. On the third and most difficult task (320-120 $\mathrm{gr} / \mathrm{in}$ ), Galago was vastly inferior to Macaca in errors to criterion and in that two of the eight animals failed to master the most difficult task after more than 20 sessions. On texture tasks, $G a$ lago error scores during acquisition still reflected both "order of testing" and "order of difficulty" effects. On the texture ALLS task Galago performed significantly lower than Macaca on four of the six (and on all the most difficult) comparisons as well as on the overall average for the ALLS task. The significantly inferior skills of Galago on texture comparisons strongly suggest a real sensory deficit on these tasks, known to depend upon cutaneous input to area 1 in Macaca (Randolph and Semmes, 1974; Carlson, 1981). These results are consistent with previous research and the theoretical position that the evolution of the second projection from the glabrous hand to area 1 in Macaca provides for greater capacity to discriminate textured surfaces.

\section{Texture discrimination capacity in Saimiri and Cebus}

As both NW species have a second projection from the glabrous hand to arca 1 as in Macaca, it was expected that some similarity would be seen among the three anthropoids and all would be superior to Galago on texture tasks. However, the details of SI maps in Cebus are more similar to Macaca in that the digits project to the entire anterior-posterior expanse of areas $3 \mathrm{~b}$ and 1 (Fig. 4; Nelson et al., 1980; Felleman et al., 1983). By contrast, in SI hand area of Saimiri the digits and palm fields both project to those areas, resulting in a relatively smaller elaboration of the digit surfaces than in Macaca and Cebus (Fig. 4; Sur et al., 1982)

Saimiri and Cebus showed an efficiency and rate of learning on texture tasks that were no different from that of Galago. It is clear from the results presented here that both Saimiri and Cebus had difficulty in learning to discriminate between textured surfaces. This difficulty in learning is best illustrated by the finding that two of the four Saimiri and one of the two normal Cebus never mastered the 320-120 gr/in comparison mastered by all Macaca and six of the eight Galago. Both Saimiri and Cebus had a substantially slower rate of learning on texture tasks and their efficiency was significantly lower than that of Macaca. Thus, neither Saimiri nor Cebus exhibited the behavioral ben- 
efits expected from having an expanded and complex glabrous projections to area 1 . On the texture ALLS task, Saimiri and Cebus also behaved similarly to Galago, and Cebus on average performed strikingly below the level of Galago. Compared to Macaca, both Saimiri and Cebus were significantly inferior on texture performance comparisons.

The lack of relevance of the glabrous input to area 1 for texture discrimination capacity in Cebus was seen in the inferior performance of normal animals and when the same two Cebus were retested following an area 1 lesion. Rather than producing a texture-specific deficit as in Macaca after the area 1 lesion, Cebus showed a remarkable improvement in performance on texture discrimination tasks. The generality of this improvement is shown in that they mastered a difficult comparison (320-120 $\mathrm{gr} / \mathrm{in}$ ) with fewer errors than they had taken to learn less difficult ones preoperatively. Surprisingly, the animal (Cbl) that had failed to master that comparison during previous training did so after removal of area 1 . The other Cebus $(\mathrm{Cb} 2)$ relearned more quickly and efficiently after area 1 lesions in both hemispheres than during original learning. That previous discrimination experience cannot account for the failure to find deficits after area 1 lesion is shown in that the efficiency of acquisition and performance on the ALLS task on the hand that was not previously trained $(\mathrm{Cb} 2 \mathrm{c})$ exceeded that of the previously trained hand following a lesion in contralateral area $1(\mathrm{Cb} 2 \mathrm{~b})$.

Although our original finding relating deficits on texture tasks to area 1 in Macaca was based on animals trained only postoperatively (Semmes and Randolph, 1974), in a subsequent study the same selective deficits for texture tasks following an area 1 removal were demonstrated in animals also trained preoperatively (Carlson, 1981). Those animals failed to reacquire the same 320-180 gr/in that Cebus-area 1 mastered in the present study and with the same efficiency as normal Macaca on this same comparison (Carlson, 1984). These findings strongly suggest that the expansion and duplication of glabrous input to SI in Cebus does not contribute to texture discrimination capacity as it does in Macaca. Rather, the processing of glabrous input within area 1 of Cebus may compete or interfere with tasks requiring attending to details of surface texture. Area 1 in NW anthropoids may have evolved to process glabrous input for nontexture capacities that would serve to detect tactile features not represented in the type and range of comparisons used in these tasks.

The significance of receptor number and modality in the final SI and SII topography in the size of SI and SII

A comparative issue of major significance for the development, evolution, and behavioral capacity of the somatic sensory system is the nature of sensory receptors in the skin of these species. The dermis of Galago crassicaudatus (now G. garnetti) is characterized by a dense network of sensory end-organs in the glabrous hand and foot. These resemble the generalized mammalian end-organs more than the specialized Meissner corpuscles, found in digit tips of anthropoids, including apes and humans. The specialized end-organs associated with hairs in Galago are also described as primitive, though abundant, in hairy skin (Montagna and Yun, 1961). In Macaca numerous Meissner corpuscles are found in the glabrous surface of the hand and foot, with digits having a higher density than palm and sole (Montagna et al., 1964). The greater density of Meissner corpuscles in glabrous skin of Macaca than of mammalian end- organs in the skin of Galago is consistent with the overall greater magnification of glabrous skin projections in SI and SII of $\mathrm{Ma}$ caca. It is also expected that this difference in receptor density between these species, between the hand and foot, and between glabrous and hairy skin may contribute to the development of the different topographic patterns seen in SI and SII of these species.

The dermis of Saimiri contains Meissner corpuscles as well as another type of papillary nerve end-organ (Machida et al., 1967). The skin of Cebus is described to resemble that of Saimiri, with Meissner corpuscles common in digits and pacinian corpuscles in the palm and soles but rarely in the digits (Perkins and Ford, 1969). Saguinus and Callithrix are also found to have Meissner corpuscle in the skin of hand and foot, but (consistent with a single SI areas) the skin of these Callithrichidae is described as "between that of the Prosimii and Anthropoidea" (Perkins, 1968, 1969). To confuse the already muddled picture of primitive and derived features in brain, hand, behavior, and phylogeny of the NW anthropoids, Aotus (characterized by two cutaneous SI areas) has some receptors in the glabrous skin that "resemble" Meissner corpuscles but the overall features of the skin led to the conclusion that some NW species (and particularly Aotus) might be "considered to be New World Prosimii" (Hanson and Montagna, 1962). Although the NW primates represent an interesting variety of adaptations to arboreal living among primates, the continuing confusion around the phyletics of this infraorder, illustrated here by the inconsistencies in primitive and derived traits of the hand and CNS, makes it difficult to interpret the similarities and differences among NW and OW primates from an evolutionary perspective.

\section{Relevance of natural behaviors to formal tests of tactile capacity}

Comments on the natural behavioral repertoires of the four species used in this study seem warranted as a background for evaluation of the apparent sensory differences between species on formal tasks and of differences in brain organization. The prosimian Galago is a nocturnal primate that occupies arboreal settings at all levels of the forests. The home ranges of several adult females overlap with that of a single adult male but, except for mother-daughter pairs, adults are found together only during breeding season. The locomotor pattern typical of G. garnetti consists primarily of quadrupedal walking and running, less often by leaping, characteristic of the smaller $G$. senegelensis. Their diet consists mainly of tree gums, obtained by using the teeth, but fruits and insects, which require greater use of their manual capacities, are also important food sources (Bearder, 1987). There is limited social use of the hand, as grooming is performed using lower incisors and infants are transported by mouth.

In contrast, Macaca mulatta characteristically live in large multimale-multifemale social groups, ranging from 10 to 90 individuals. The total group size in $M$. mulatta appears to vary as a function of availability of resources in a particular habitat. $M$. mulatta are found in a variety of habitats in Asia ranging from urban settings (towns, temples, markets, and train stations) to forested areas. It is a terrestrial species and typically shows a quadrupedal form of locomotion illustrated in Figure 1. The hand is used in a multitude of ways in these diverse habitats as the foraging style of Macaca is that of an opportunistic omnivore (Ashmore DeClue, 1992). The social use of hand in Macaca is 
a prominent part of their natural repcrtoire as they may spend as much as $25 \%$ of their day participating in social grooming. Overall, females spend more time grooming than males, whose grooming rate is strongly correlated with breeding season (Goosen, 1987).

Like Galago, Cebus and Saimiri are arboreal and their hands and feet are adapted for locomotion in trees. Cebus spend most of its time in the tree canopy but also frequently come to the ground while foraging or traveling (Fleagle et al., 1981; Robinson and Janson, 1987). Cebus uses supports ranging in diameter between 2 and $10 \mathrm{~cm}$, and during locomotion shows prehensile abilities with its hands and feet. Saimiri is more often found in the lower canopy and forest understory, typically moving along narrow branches and lianas ( $<2 \mathrm{~cm}$ in diameter). Its locomotor pattern is slightly different from Cebus in that it spends a greater amount of time leaping and climbing (Fleagle et al., 1981). Perhaps the acuity to sense size differences is most developed in arboreal primates, but does not become degenerate as species make terrestrial adaptations, like Macaca mulatta, whose ancestors are believed to have been arboreal.

Of the two NW species, only Cebus uses precision grip, as defined by the capacity to manipulate objects between the thumb and digit tips, or between digit tips, without use of the palm. Saimiri uses only a power grip by which objects are held by flexing fingers against the palm (Costello and Fragaszy, 1988). Based on the diversity of prehensile patterns in object manipulation, Torigoe (1985) ranked Cebus with the great apes, as showing more diverse abilities than other NW and $\mathrm{OW}$ anthropoids. Although $90 \%$ of all manipulations were done with the glabrous part of the hand, Cebus tended to use its digits less (and palms more) than Macaca and apes (Torigoe, 1985). It has been suggested that the manipulative skills of Cebus are in part due to its feeding adaptation of extractive foraging (Thorington, 1966; Parker and Gibson, 1977). When foraging they make extensive use of their hands when searching for imbedded food items and hidden insects and require great strength to gain access to pith and nuts (Robinson and Janson, 1987). The diet of Saimiri consists mainly of fruits (especially figs) and insects. Insects are usually caught, using power grip (similar to that of Galago) while the animal is in motion. Social grooming is uncommon among Saimiri (Baldwin and Baldwin, 1981), while the amount of time Cebus spends in social grooming (I7awa, 1980; Robinson and Janson, 1987) approaches that of Macaca mulatta (Ashmore DeClue, 1992).

If the prominent, and undoubtedly important, glabrous input from the hand to area 1 does not mediate texture discrimination capacity, then to what type of sensory ability might this area contribute in NW anthropoids? Review of the species-typical patterns of hand use of these primates may lead to some predictions about classes of cutaneous processing that might be achieved by these species relative to Macaca and Galago. By examining their behaviors in the wild, as well as their manipulative capacity under formal tests in captivity, it may be possible to reach an understanding of the extent of their hand use and why texture discrimination capacity may be less important in the natural behavioral repertoire of Saimiri and Cebus than for Macaca. In Cebus, but not Saimiri, the SI hand area is vastly increased in size relative to the actual skin area and relative to the SI foot area. This finding suggests that these species that occupy the same natural habitats are using their forelimbs differently, but in a manner that might provide clues as to what tactile skills to investigate in captive Cebus.
Relevance to the evolution of neocortex to general behavioral capacities

A few remarks about the literature on the general relationship between evolution of neocortex and general behavioral capacity seem warranted, particularly with regard to Cebus. A clear evolutionary trend seen in primates is the expansion in brain size beyond the general mammalian scale (Jerison, 1973; Falk, 1980). It is generally believed that diet influences brain size in primates (e.g., Harvey et al., 1987; Milton, 1988). Recently, Sawaguchi (1992) reported that both diet and social structure are significantly correlated with the relative size of neocortex (RSN) over a wide range of primate species. Anthropoids with a predominantly frugivorous (fruit-based) diet had a greater RSN than folivorous (leaf-eating) anthropoids, and polygynous anthropoids had a greater RSN than monogynous anthropoids. Howcver, as Dunbar (1992) points out, it may not be the mating system per se that is associated with elaborated neocortical areas but rather the size of the social group and complexity of the social interactive networks. Determination of the specific role of tactile information and manual dexterity in these general behavioral strategies could benefit from field observations that specifically attend to the sensorimotor functions of the hand in locomotor, feeding, and social behaviors.

It has been suggested that the living members of the Cebidae family, including Saimiri and Cebus, are the most generalized and therefore most likely reflective of the earliest NW anthropoids (Ford, 1986; Kay, 1990). On the other hand, Hershkovitz (1977) believes that many of the morphological features seen in Saguinus, and other callitrichids, are primitive traits. Others suggest that sometime during its evolutionary history the callitrichid family underwent a rapid reduction in body size, suggesting that many of their traits arc derived, not primitive (Ford, 1980; Sussman and Kinsey, 1984). However, the brain of Saguinus shows very simple sulcal patterns, similar to the brains of prosimians, and compared to other NW primates, its brain shows the most primitive form (Falk, 1980; Carlson et al., 1986). The sulci pattern of the Cebus brain is intermediate in complexity to the prosimian-like Callitrichidae and the more complex Atelinae (Falk, 1980) and more complex than Saimiri. Stephan (1972) found that the neocortical progression index (calculated from neocortical size in relation to that of a basal insectivore) of Cebus was the same as for chimpanzee (60) but higher than Macaca (46) and Saimiri (43). Galago was approximately average for prosimians and had a neocortical progression index of 14

The present findings suggest that an understanding of the significance of increased neocortical area, and increased cognitive and behavioral capacities, will require studies that focus on specific cortical regions and specific behavioral skills in species of different grades and clades. In fact, the differences in the magnification factor for the glabrous hands and feet even among the closely related NW anthropoids suggest that it may be necessary to consider such regional differences and body parts, as well as cortical projection areas SI or SII. The same caution for the need for greater specificity is seen in the nature of the behavioral tasks in the present experiments. These results show that discrimination of size and texture, and of different levels of difficulty within these tasks, may depend of a different constellation of peripheral receptors and central projection sites. Choosing behavioral tasks that are specific enough to relate to peripheral and central structures, yet that resemble discrimi- 
nations made in the natural habitat, is not an easy task. However, if a valid understanding of the relationship between neural organization and behavioral capacity is to be achieved, information about the natural behavioral repertoires of species must be considered.

\section{Relevance of thalamic connections to SI and SII to tactile capacity}

New insights into the possible evolutionary mechanisms by which varying patterns of SI and SII input have been achieved, in closely and distantly related species, appear from recent findings on the patterns of thalamocortical in different primates. The original conception of VPL (ventroposterior lateral nucleus; the major source of input to SI) as providing input to both SI and SII in Macaca has been modified by recent observations in a variety of species (Jones, 1985). Subsequent studies showed that the VPL projection to SII is less extensive (or lacking) in $\mathrm{Ma}$ $c a c a$, and that the projection from inferior VP (VPI) is predominant (Friedman and Murray, 1986; Friedman et al., 1986). The physiological implication of the revised VP-SII connectivity came with the demonstrations that lesions of SI hand area silenced the hand area of SII (Pons et al., 1987), substantiating the notion that SII receives its cutaneous input indirectly via intrahemispheric connections through SI. These findings are consistent with the theory of tactile processing arguing that SII serves as a point in a VP-SI-SII serial pathway to limbic cortex for higher cortical processing of tactile input in Macaca (Mishkin, 1979). Yet anatomical studies in adult Galago indicate that SII receives its major thalamic projection from ventral zones in the lateral division of VPL and SI receives its input from more dorsal regions of VPL (Burton and Carlson, 1986). Other nuclei, including VPI, also project to SII.

When the pattern of VP-SI and VP-SII connections in $\mathrm{Ma}$ caca and Galago are compared to the projection of the glabrous and hairy hand to SI, an interesting coincidence is observed. The direct VPL-SII connections seen in Galago are lacking in Macaca, while the projection of the glabrous hand to area 1 of Macaca is lacking in Galago. In Galago, the projections of both the glabrous and hairy skin are unambiguously segregated into similarly sized subdivisions in SI (to areas $3 \mathrm{~b}$ and 1 , respectively) and into the ventrodorsal subdivisions in SII. In contrast, the major glabrous input in SI and SII of Macaca obscures the minor input from the hairy hand and digits. When comparing the size of the glabrous hand areas in SI and SII, it is important to emphasize that, compared to Galago, the glabrous hand areas in SI and SII of Macaca have increased relative to the actual skin area, relative to the hairy hand surface, and relative to the cortical projection areas for the glabrous foot. To understand the cortical mechanisms that mediate the more recently evolved tactile capacities of the hand, it is important to consider both the differential cortical projections of the glabrous and hairy surfaces of the hand and the different behavioral demands on these two extremities in the behavioral strategies of Galago and Macaca in their natural habitat.

\section{Relevance of the development of thalamocortical connections in the evolution of SI and SII organization in primates complexity of SI and SII}

The absolute density of receptors in glabrous and hairy skin, as well as the different classes of receptors, can be expected to be important in development, as activity-dependent mechanisms are thought to play a major role in the elimination and main- tenance of transient connections. In the somatic sensory system the best evidence for such mechanisms operating in the development of thalamocortical projections and SI topography is from developmental studies of the SI barrel fields in rodents. The importance of whisker stimulation in the formation and maintenance of barrel fields has been seen in brainstem and thalamic nuclei as well as cortical projection areas (Van der Loos and Dörfl, 1978; Van der Loos and Welker, 1985).

The expansion and/or duplication of input to SI and SII in different primate species may result from minor variations in the developmental sequences of outgrowth, elimination, and stabilization of thalamocortical and corticocortical connections. The studies of VP-SI-SII relations in adult Macaca provide an interesting contrast to those VP projections to SI and SII in adult Galago, where we find that VPL projects both to SI and SII (Burton and Carlson, 1986). In adult Galago, individual neurons in VPL or VPI project to cither SI or SII (but not to both), whereas in the first postnatal weeks many VP neurons extend collaterals to both SI and SII (Carlson et al., 1987). A similar pattern of exuberant thalamic projection to pre- and postcentral gyrus in infant Macaca has also been described (Darian-Smith et al., 1990). A developmental mechanism that could transform a single cutaneous SI projection area (and VPL-SI and VPL and VPI-SII pattern) seen in adult Galago, to the multiple glabrous SI projection areas (VPL-SI and VPI-SII pattern) of Macaca is the robust phenomenon of stabilization of normally transient collaterals (O'Leary, 1989, 1992). If, early in development, the initial outgrowth of VPL axons is specific for neither place (SI or SII) nor submodality (glabrous or hairy), species-typical patterns of elimination and stabilization of collaterals may occur.

Our findings in infant Galago that some single VP neurons extend axon collaterals to SI or SII raise the issue of whether the segregated glabrous and hairy hand areas of SI (areas 3b and 1) and SII may come about through selective stabilization based on submodality. If glabrous and hairy inputs initially overlap in SI and SII of the infant, then the processes of elimination and stabilization of collaterals could result in segregation into glabrous-hairy divisions and in selective projection of VPL neurons to SI or SII in adult Galago. To achieve the latter pattern all VPI collaterals to SI would be eliminated and those to SII stabilized.

If in Macaca the initial outgrowth of thalamic axons also occurs without respect to place (SI or SII) or submodality (glabrous or hairy), a species-typical pattern may result from the elimination of all VPL collaterals to SII, with the maintenance of the remaining VPL collaterals to SI, and the maintenance of all VPI collaterals to SII. A second part of this developmental pattern would be the glabrous input from VPL (predominant in Macaca), which would dominate over the sparser hairy input from the hand, with the all VPL-mediated glabrous input projecting to areas $3 b$ and 1 , rather than divided between SI and SII as in adult Galago.

Primate studies seeking to demonstrate the evolution and development of brain structure and behavioral function need to be as inclusive as the investigations of rodent barrel fields and of SI in carnivores (Welker et al., 1963, 1964) to approach an understanding of brain and behavior relations. The present study raises issues that must be addressed to address the complex brain-behavior relations in this restricted domain of the somatic sensory system as well as for more general behavioral categories. Convergent information is needed from the classical 
theoretical debates to current research findings in evolutionary and developmental biology, along with comparative psychology and physical anthropology, to approach these brain-behavior relations in primates.

Differences between the earlier-evolved Galago and the more recently evolved Macaca must also be considered in a developmental perspective, as it is variation in development of such connections that contribute to the species-typical cortical organization observed in adult animals (deBeer, 1958; Gould, 1977; Carlson, 1990, 1991). In order to account for the behavioral significance of structural and functional features of cerebral cortex, the combined analyses of peripheral receptors, cortical magnification factors, as well as topography and submodality data must be made to begin an understanding of species differences in behavioral capacity. The now classical studies of Welker et al. $(1963,1964)$ in carnivores set a standard for the level of detail at all levels of a sensory system required to obtain an understanding of the role of cerebral cortex in the evolution of (or in individual differences) in behavioral capacity.

\section{References}

Ashmore DeClue PC (1992) Macaques: an adaptive array. PhD thesis, Washington University, St. Louis.

Baldwin JD, Baldwin JI (1981) The squirrel monkeys, genus Saimiri. In: Ecology and behavior of neotropical primates, Vol 1 (CoimbraFilho AF, Mittermeier RA, eds), pp 277-330. Rio de Janeiro: Academia Brasileira de Ciencias.

Bearder SK (1987) Lorises, bushbabies, and tarsier: diverse societies in solitary foragers. In: Primate societies (Smuts BB, Cheney DL, Seyfarth RM, Wrangham RW, Struhsaker TT, eds), pp 11-24. Chicago: Chicago UP.

Biegert J (1961) Volarhaut der Hände und Füsse. In: Handbook of primatology, Vol 2 (Schultz AH, Starck D, eds). New York: Karger.

Bishop A (1964) Use of the hand in lower primates. In: Evolutionary and genctic biology of primates, Vol 2 (Buettner-Janusch $J$, ed), pp 133-225. New York: Academic.

Burton H, Carlson M (1986) Second somatic sensory area (SII) in the prosimian primate, Galago crassicaudatus. J Comp Neurol 247:200220.

Carlson M (1981) Characteristics of sensory deficits following lesions of Brodmann's areas 1 and 2 in the postcentral gyrus of Macaca mulatta. Brain Res 204:424-430.

Carlson M (1984) Development of tactile discrimination capacity in Macaca mulatta. I. Normal infants. Dev Brain Res 16:69-82.

Carlson M (1985) The significance of single or multiple cortical areas for tactile discrimination in primates. In: Hand function and the neocortex (Goodwin AW, Darian-Smith I, eds), pp 1-16. Berlin: Springer.

Carlson M (1990) Rolc of somatic sensory cortex in tactile discrimination in primates. In: Cerebral cortex, Vol $8 \mathrm{~b}$ (Jones EG, Peters A, eds), pp 451-486. New York: Plenum.

Carlson M (1991) Ontogenetic and phylogenetic perspectives on somatic sensory cortex and tactile function. In: Wenner-Gren International symposium series, Informational processing in the somatosensory system (Franzen O, Westman J, eds), pp 177-192. Hampshire, UK: Macmillian.

Carlson M, Burton H (1988) Recovery of tactile function after damage to primary or secondary somatic sensory cortex in infant Macaca mulatta. J Neurosci 8:833-859.

Carlson M, FitzPatrick KA (1982) Organization of the hand area in the primary somatic sensory cortex (SmI) of the prosimian primate, Nycticebus coucang. J Comp Neurol 204:280-295.

Carlson M, Welt C (1977) Singlc rcpresentation of the hand in somatic sensory cortex (SI) of prosimian, Galago crassicaudatus. Soc Neurosci Abstr 3:1524.

Carlson M, Welt C (1980) Somatic sensory cortex (SmI) of the prosimian primate Galago crassicaudatus: organization of mechanoreceptive input from the hand in relation to cytoarchitecture. J Comp Neurol 189:249-271.

Carlson M, Welt C (1981) Somatic sensory cortex (SmI) in prosimian primates. In: Cortical sensory organization, Vol I (Woolsey CN, ed), pp 1-27. Clifton, NJ: Humana.

Carlson M, Heurta MF, Cusick CG, Kaas JH (1986) Studies on the evolution of multiple somatosensory representations in primates: the organization of anterior parietal cortex in the New World callitrichid, Saguinus. J Comp Neurol 246:409-426.

Carlson M, O'Leary DDM, Burton H (1987) Potential role of thalamocortical connections in recovery of tactile function following somatic sensory cortex lesions in infant primates. Soc Neurosci Abstr 13:25.2.

Chevalier-SkolnikoffS (1989) Spontaneous tool use and sensorimotor intelligence in Cebus compared with other monkeys and apes. Behav Brain Sci 12:561-627.

Costello MB, Fragaszy DM (1988) Prehension in Cebus and Saimiri. I. Grip type and hand preference. Am J Primatol 15:235-245.

Darian-Smith C, Darian-Smith I, Surindar SC (1990) Thalamic projections to sensorimotor cortex in the newborn macaque. J Comp Neurol 299:47-63.

deBeer G (1958) Embryos and ancestors. Oxford: Clarendon.

Delson E, Rosenberger AL (1980) Phyletic perspective on platyrrhine origins and anthropoid relationships. In: Evolutionary biology of the New World monkeys and continental drift (Ciochon RL, Chiarelli $\Lambda \mathrm{B}$, eds), pp 445-458. New York: Plenum.

Dunbar RIM (1992) Neocortex size as a constraint on group size in primates. J Hum Evol 20:469-493

Falk D (1980) Comparative study of the endocranial casts on New and Old World monkeys. In: Evolutionary biology of the New World monkeys and continental drift (Ciochon RL, Chiarelli AB, eds), pp 275-292. New York: Plenum.

Felleman DJ, Nelson RJ, Sur M, Kaas J (1983) Organization of the somatosensory cortex in cebus monkey. Brain Res 268:15-26.

FitzPatrick KA, Carlson M, Charlton J (1982) Topography, cytoarchitecture and sulcal patterns in primary somatic sensory cortex $(\mathrm{SmI})$ of the prosimian primate, Perodicticus potto. J Comp Neurol 204 : 296-310.

Fleagle JG (1988) Primate adaptation and evolution. New York: Academic.

Fleagle JG, Rosenberger AL (1990) Platyrrhine fossil record. New York: Academic.

Fleagle JG, Mittermeier RA, Skopec AL (1981) Differential habitat use by Cebus apella and Saimiri sciureus in central Surinam. Primates 22:361-367.

Ford SM (1980) Phylogenetic relationships of the platyrrhini: the evidence of the femur. In: Evolutionary biology of the New World monkeys and continental drift (Ciochon RL, Chiarelli AB, eds), pp 317-329. New York: Plenum.

Ford SM (1986) Systematics of the New World monkeys. In: Comparative primate biology, Vol 1, Systematics, evolution and anatomy (Swindler DR, Erwin J, eds), pp 73-136. New York: Liss.

Friedman DP, Murray EA (1986) Thalamic connectivity of the second somatosensory area and the neighboring somatosensory cortical fields of the lateral sulcus of the monkey. J Comp Neurol 252:348-373.

Friedman DP, Murray EA, O'Neil JB, Mishkin M (1986) Cortical connections of the somatosensory fields of the lateral sulcus of macaques. Evidence for a corticolimbic pathway for touch. J Comp Neurol 252:323-347.

Gibson KR (1986) Cognition, brain size and the extraction of embedded food resources. In: Primate ontogeny, cognition and social behaviour (Else JG, Lee PC, eds), pp 93-103. New York: Cambridge UP.

Goosen C (1987) Social grooming in primates. In: Comparative primate biology, Vol 2B, Behavior, cognition and motivation (Mitchell G, Erwin J, eds), pp 107-131. New York: Liss.

Gould SJ (1977) Ontogeny and phylogeny. Cambridge, MA: Harvard UP.

Hanson G, Montagna W (1962) The skin of primates. XII. The skin of the owl monkcy (Aotus trivirgatus). Am J Phys Anthropol 20:421430.

Harvey PH, Martin RD, Clutton Brock TH (1987) Life histories in comparative perspective. In: Primate societies (Smuts BB, Cheney DL, Seyfarth RM, Wrangham RW, Struhsaker TT, eds), pp 181-196. Chicago: Chicago UP.

Hershkovitz P (1977) Living New World monkeys (Platyrrhini), with an introduction to primates, Vol 1. Chicago: Chicago UP. 
Izawa K (1980) Social behavior of the wild black-capped capuchin (Cebus apella). Primates 21:443-467

Jerison HJ (1973) Evolution of the brain and intelligence. New York: Academic.

Jones EG (1985) The thalamus. New York: Plenum.

Kay RF (1990) The phyletic relationships of extant and fossil Pitheciinae (Platyrrhini, Anthropoidea). J Hum Evol 19:175-208.

Klüver $\mathrm{H}$ (1937) Re-examination of implement-using behavior in a Cebus monkey after an interval of three years. Acta Psychol 2:347397.

Macdonald D (1984) The encyclopedia of mammals. New York: Facts on File.

Machida H, Perkins E, Hu F (1967) The skin of Primates. XXXV. The skin of the squirrel monkey (Saimiri sciurea). Am J Phys Anthropol 26:45-54.

Merzenich MM, Kaas JH, Sur M, Lin C-H (1978) Double representation of the body surface within cytoarchitectonic areas $3 \mathrm{~b}$ and 1 in "SI" in the owl monkey Aotus trivirgatus. J Comp Neurol 181:4174.

Merzenich MM, Nelson RJ, Kaas JH, Stryker MP, Jenkins WM, Sur M, Zook JM, Cynader MA, Schoppmann A (1987) Variability in hand surface representations in areas $3 \mathrm{~b}$ and 1 in adult owl and squirrel monkeys. J Comp Neurol 258:281-296.

Milton K (1988) Foraging behaviour and the evolution of primate intelligence. In: Machiavellian intelligence (Byrne R, Whiten A, eds), pp 285-305. Oxford: Oxford UP.

Mishkin M (1979) Analogous neural models for tactual and visual learning. Neuropsychology 17:139-151.

Montagna W, Yun JS (1961) The skin of primates. VII. The skin of the great bushbaby (Galago crassicaudatus). Am J Phys Anthropol 20:149-166.

Montagna W, Yun JS, Machida H (1964) The skin of primates. XVIII. The skin of the rhesus monkey (Macaca mulatta). Am J Phys Anthropol 22:307-320.

Murray EA, Mishkin M (1984) Relative contributions of SII and area 5 to tactile discrimination of monkeys. Behav Brain Res 11:67-84.

Napier JR, Walker AC (1967) Vertical clinging and leaping-a newly recognized category of locomotor behaviour of primates. Folia Primatol 6:204-219.

Nclson RJ, Sur M, Fcllcman DJ, Kaas JH (1980) Representations of the body surface in postcentral parietal cortex of Macaca fascicularis. J Comp Neurol 192:611-643.

O'Leary DDM (1989) Do cortical areas emerge from protocortex? Trends Neurosci 12:400-406.

O'Leary DDM (1992) Development of connectional diversity and specificity in the mammalian brain by the pruning of collateral projections. Curr Opin Neurobiol 2:70-77.

Parker ST, Gibson KR (1977) Object manipulation, tool use and sensorimotor intelligence as feeding adaptations in Cebus monkeys and great apes. J Hum Evol 6:623-641.

Paul RL, Merzenich M, Goodman H (1972) Representation of slowly and rapidly adapting cutaneous mechanoreceptors of the hand in Brodmann's areas 3 and 1 of Macaca mulatta. Brain Res 36:229249.

Perkins EM (1968) The skin of primates. XXXVI. The skin of the pigmy marmoset - Callithrix (=Cebuella) pygmaea. Am J Phys Anthropol 29:349-364.

Perkins EM (1969) The skin of primates. XL. The skin of the cottontop pinché (Saguinus (=Oedipomidas) oedipus. Am J Phys Anthropol 30: 13-28.

Perkins EM, Ford DM (1969) The skin of primates. XXXIX. The skin of the white-browed capuchin (Cebus albifrons). Am J Phys Anthropol 30:1-12.

Phillips-Conroy JE, Jolly CJ, Nystrom P (1986) Dermatoglyphics as a means to identifying individuals in a baboon population. Int $\mathbf{J}$ Primatol 7:435-447

Pons TP, Garraghty PE, Friedman DP, Mishkin M (1987) Physiological cvidence for scrial processing in somatosensory cortex. Science 237:417-420.
Powell TPS, Mountcastle VB (1959) Some aspects of the functional organization of the cortex of the postcentral gyrus of the monkey: a correlation of findings obtained in a single unit analysis with cytoarchitecture. Bull Johns Hopkins Hosp 105:133-162.

Radinsky L (1974) Prosimian brain morphology: functional and phylogenetic implications. In: Prosimian biology (Martin RD, Doyle GA, Walker AC, eds), pp 781-798. Pittsburgh: Pittsburgh UP.

Randolph M, Semmes J (1974) Behavioral consequences of selective subtotal ablations in the postcentral gyrus of Macaca mulatta. Brain Res 70:55-70.

Ridley RM, Ettlinger G (1976) Impaired tactile learning and retention after removals of the second somatic sensory projection cortex (SII) in the monkey. Brain Res 109:656-660.

Ridley RM, Ettlinger G (1978) Further evidence of impaired tactile learning after removals of the second somatic sensory projection cortex (SII) in the monkey. Exp Brain Res 31:475-488.

Robinson CJ, Burton H (1980) Somatotopographic organization in the second somatosensory area of $M$. fascicularis. J Comp Neurol 192:43-67.

Robinson JG, Janson CH (1987) Capuchins, squirrel monkeys and atelines: socioecological convergence with Old World primates. In: Primate societies (Smuts BB, Cheney DL, Seyfarth RM, Wrangham RW, Struhsaker TT, eds), pn 11-24. Chicago: Chicago IJP.

Sawaguchi T (1992) The size of the neocortex in relation to ecology and social structure in monkeys and apes. Folia Primatol 58:131145.

Schwarz DWF, Deecke L, Fredrickson JM (1973) Cortical projection of group I muscle afferents to areas $2,3 \mathrm{a}$ and vestibular field in the rhesus monkey. Exp Brain Res 17:516-526.

Semmes J, Mishkin M (1965) Somatosensory loss in monkeys after ipsilateral cortical ablation. J Neurophysiol 23:473-486.

Semmes J, Porter L (1972) A comparison of precentral and postcentral cortical lesions on somatosensory discrimination in the monkey. Cortex 8:249-264.

Stephan H (1972) Evolution of primate brains: a comparative anatomical investigation. In: The functional and evolutionary biology of primates (Tuttle R, ed), pp 155-174. New York: Aldine-Atherton.

Sur M, Nelson RJ, Kaas JH (1980) The representation of the body surface in somatic koniocortex in the prosimian (Galago senegelensis). J Comp Neurol 180:381-402.

Sur M, Nelson RJ, Kaas JH (1982) Representation of the body surface in cortical areas $3 \mathrm{~b}$ and 1 of squirrel monkeys: comparisons with other primates. J Comp Neurol 211:177-192.

Sussman RW, Kinzey WG (1984) The ecological role of the Callitrichidae: a review. Am J Phys Anthropol 64:419-449.

T'euber H-L (1955) Physiological psychology. Annu Rev Psychol 6:267296.

Thorington RW Jr (1966) Feeding and activity of Cebus and Saimiri in a Columbian forest. In: Progress in primatology (Stark D, Schneider R, Kuhn JJ, eds), pp 180-184. Stuttgart: Fischer.

Torigoe T (1985) Comparison of object manipulation among 74 species of non-human primates. Primates 26:182-194.

Van der Loos H, Dörfl J (1978) Does the skin tell the somatosensory cortex how to construct a map of the periphery? Neurosci Newsl 7:2330.

Van der Loos H, Welker E (1985) Development and plasticity of somatosensory maps. In: Development, organization and processing in somatosensory pathways (Rowe $\mathrm{M}$, Willis WD Jr, eds), pp 53-67. New York: Liss.

Welker WI, Campos GB (1963) Physiological significance of sulci in somatic sensory cerebral cortex in mammals of the family Procyonidae. J Comp Neurol 120:19-36.

Welker WI, Johnson JI Jr, Pubols BH Jr (1964) Some morphological and physiological characteristics of the somatic sensory system in raccoons. Am Zool 4:75-94.

Woolsey CN, Marshall WH, Bard P (1942) Representation of cutaneous tactile sensibility in cerebral cortex of the monkey as indicated by evoked potentials. Bull Johns Hopkins Hosp 70:399-441. 